$$
\begin{gathered}
\text { Universidade de São Paulo } \\
\text { Instituto de Física de São Carlos }
\end{gathered}
$$

Guilherme David Araujo

\title{
Jogos evolucionários de reciprocidade indireta via interações opcionais
}





\section{Guilherme David Araujo}

\section{Jogos evolucionários de reciprocidade indireta via interações opcionais}

Dissertação apresentada ao Programa de PósGraduação em Física do Instituto de Física de São Carlos da Universidade de São Paulo, para obtenção do título de Mestre em Ciências.

Área de Concentração: Física Aplicada Orientador: Prof. Dr. Leonardo Paulo Maia

Versão Corrigida

(Versão original disponível na Unidade que aloja o Programa)

São Carlos 
AUTORIZO A REPRODUÇÃO E DIVULGAÇÃO TOTAL OU PARCIAL DESTE TRABALHO, POR QUALQUER MEIO CONVENCIONAL OU ELETRÔNICO, PARA FINS DE ESTUDO E PESQUISA, DESDE QUE CITADA A FONTE.

Ficha catalográfica elaborada pelo Serviço de Biblioteca e Informação do IFSC, com os dados fornecidos pelo autor

Araujo, Guilherme David

Jogos evolucionários de reciprocidade indireta via interações opcionais / GuiIherme David Araujo; orientador Leonardo Paulo Maia - versão corrigida - São Carlos, 2016.

$78 \mathrm{p}$.

Dissertação (Mestrado - Programa de Pós-Graduação em Física Aplicada) - Instituto de Física de São Carlos, Universidade de São Paulo, 2015.

1. Teoria dos jogos evolucionária. 2. Dinâmica populacional. 3. Evolução da cooperação. 4. Reciprocidade indireta. 5. Interações opcionais. I. Maia, Leonardo Paulo, orient. II. Título. 
Ao meu padrinho, Márcio Fernando David. 



\section{AGRADECIMENTOS}

Em primeiro lugar agradeço à minha mãe, Rosângela, pelo apoio e pela devoção incondicionais que dela recebo desde o começo de minha vida, resultando na ilimitada conexão que temos. Agradeço ao meu pai, Sergio, e aos meus irmãos, Letícia e Gesiel, por estarem sempre ao meu lado, dispostos a me aturar e a me ajudar. À lealdade sentimental de toda a minha família, meu maior exemplo de união.

Agradeço muito ao Léo, meu orientador, por me acolher em um momento difícil e me entender tão bem. Mesmo com bem menos tempo do que o normal, ele me ensinou muito mais do que eu poderia esperar de um mestrado completo. Os dez conselhos mais valiosos que tive a oportunidade de ouvir na universidade com certeza foram dele. Léo, Obrigado por ser uma das raras pessoas que eu sinceramente respeito, por ser alguém que eu chamei de orientador usando o significado da palavra.

Agradeço à Gaby, ao Rafael e ao lago pela amizade e pelo carinho de todos esses anos, me ajudando com as coisas mais banais e as mais sérias, atravessando comigo o abismo e compartilhando comigo a luz da existência. Vivi, além de tudo isso, agradeço a você por descobrir o amor comigo, por ser a minha maior motivação; obrigado, minha querida, por me escolher. Nossa sintonia é o que há de mais gostoso na minha vida.

Em especial, pela ajuda na real elaboração da minha dissertação, agradeço ao Léo pela insubstituível orientação, à Vivi por cuidar de mim durante esses últimos dois meses de elaboração, à Kríssia pela paciência e por todos os seus ensinamentos sobre Latex e ao Rafael pela ajuda gráfica e motivacional. Sem qualquer um de vocês, este trabalho não estaria pronto no tempo certo.

Obrigado à USP e ao IFSC pela oportunidade, por efetivamente serem minha segunda casa. E à CAPES pelo financiamento do meu projeto; obrigado. 
Agradeço a todos os que já morreram, cujo legado eu e toda minha geração herdamos, através de seu esforço e obsessão. Acima de tudo, agradeço aos meus genes, pelo trabalho e o interesse de me montar como sou, de me permitir experimentar. 


\section{RESUMO}

ARAUJO, G. D. Jogos evolucionários de reciprocidade indireta via interações opcionais. 2016. 78 p. Dissertação (Mestrado em Ciências) - Instituto de Física de São Carlos, Universidade de São Paulo, São Carlos, 2016.

Em uma perspectiva evolutiva, a emergência e a manutenção de comportamentos altruísticos e de cooperação não é de fácil entendimento. O impulso por ajudar um indivíduo desconhecido não pode significar um prejuízo na capacidade reprodutiva, o que muitas vezes parece ser o mais óbvio. Muito se tem feito no sentido de compreender os ganhos indiretos da cooperação, ou o que se espera em retorno por este comportamento. A espera por reciprocidade é um dos modos de se tornar a cooperação atraente. Os seres humanos possuem uma capacidade singular de expandir a reciprocidade para interações organizadas em que não necessariamente se recebe a retribuição de um favor, mas sim o favor de um terceiro indivíduo. Para estes sistemas, de reciprocidade indireta, são necessários elaborados processos cognitivos que sustentam uma capacidade para linguagem, julgamentos morais e organização social. Entende-se que esta forma de cooperação é um fator essencial para a evolução do intelecto e da estrutura social atuais dos seres humanos. A teoria dos jogos evolucionária é uma ferramenta matemática muito utilizada na sistematização analítica dos problemas envolvendo cooperação e processos evolutivos no geral. A capacidade reprodutiva é traduzida em termos de funções matemáticas, sendo possível realizar dinâmicas populacionais que modelam a pressão seletiva. Neste trabalho, utilizamos métodos de teoria dos jogos evolucionária para explorar modelos de reciprocidade indireta, expandindo o tratamento de um modelo para interações opcionais envolvendo estratégias de cooperadores condicionais. Mostramos que a presença de coopera- 
dores incondicionais ameaça a estabilidade da cooperação e que erros de execução podem ser uma solução.

PALAVRAS-CHAVE: Teoria dos jogos evolucionária. Dinâmica populacional. Evolução da cooperação. Reciprocidade indireta. Interações opcionais. 


\section{ABSTRACT}

ARAUJO, G. D. Evolutionary games of indirect reciprocity by optional interactions. 2016.78 p. Dissertação (Mestrado em Ciências) - Instituto de Física de São Carlos, Universidade de São Paulo, São Carlos, 2016.

At an evolutionary perspective, the emergence and maintenance of altruistic and cooperative behaviours is of no easy understanding. The impulse of helping an unrelated individual cannot mean a loss of reproductive fitness, as many times may seem the obvious. Much has been done in the way of knowing the indirect benefits of cooperation, or what to expect in retribution for this behaviour. To expect reciprocity is one way of looking at cooperation as more attractive. Human beings have a singular capacity of expanding reciprocity to organized interactions where retribution of a favour is not necessary, but one can expect the favour of a third-party. For these systems, of indirect reciprocity, elaborate cognitive processes are necessary, ones that maintain the capacity for language, moral judgements and social organization. One can understand this form of cooperation as an essential factor for the evolution of humans nowadays' intellect and social structure. Evolutionary game theory is a mathematical tool that is largely used in the analytical systematization of problems involving cooperation and evolutionary processes in general. Reproductive fitness is understood in terms of mathematical functions, making possible the work on population dynamics that model selective pressure. In this work, we use methods in evolutionary game theory to explore models of indirect reciprocity, expanding the treatment of a model for optional interactions involving conditional cooperators strategies. We show that the presence of unconditional cooperators threatens the stability of cooperation and that execution errors might be a solution. 
KEYWORDS: Evolutionary game theory. Population dynamics. Evolution of cooperation. Indirect reciprocity. Optional interactions. 


\section{Sumário}

Capítulo 1 Introdução

1.1 Mecanismos da evolução . . . . . . . . . . . . . . . . . . . . . 13

1.2 Cooperação . . . . . . . . . . . . . . . . . . . . . . . . . 16

1.3 Reciprocidade indireta . . . . . . . . . . . . . . . . 18

1.4 Teoria dos jogos evolucionária . . . . . . . . . . . . . . . . . . . 20

Capítulo 2 Modelos anteriores . . . . . . . . . . . . . 25

2.1 Modelo de Nowak e Sigmund . . . . . . . . . . . . . . . . . . . 25

2.2 Modificações no modelo de Nowak e Sigmund . . . . . . . . . . . . . 29

2.3 Interações opcionais . . . . . . . . . . . . . . . . . . . . . . . 32

Capítulo 3 Resultados . . . . . . . . . . . . . . . . . 37

3.1 Resolução da relação $f_{n}=A f_{n-1}+B \ldots \ldots \ldots \ldots \ldots$

3.2 Reobtenção dos payoffs para interações opcionais . . . . . . . . . . 39

3.3 Dinâmica considerando a estratégia All-C . . . . . . . . . . . 42

3.4 Erros de execução na cooperação . . . . . . . . . . . . . . . . 52

3.5 Má reputação nas interações entre exploradores . . . . . . . . . . . . 62

3.6 Um modelo para informação incompleta . . . . . . . . . . . . . . 67 
Capítulo 4 Conclusões

Referências 


\section{Capítulo 1}

\section{Introdução}

Neste capítulo, construímos a motivação por trás da análise deste trabalho. Na primeira seção, apresentamos um entendimento dos mecanismos que compõem os processos evolutivos e como, a partir deles, é gerado um interessante problema a respeito dos comportamentos de cooperação. Depois, descrevemos mais detalhadamente esta questão para em seguida introduzir o conceito de reciprocidade indireta, a forma de cooperação que este trabalho tem como foco. Por fim, explicamos as ideias da teoria dos jogos evolucionária (em inglês, evolutionary game theory, usaremos a sigla EGT) de forma resumida, destacando os aspectos da teoria que são utilizados aqui.

\subsection{Mecanismos da evolução}

Desde o surgimento da teoria sintética, com a combinação da teoria da seleção natural de Charles Darwin ${ }^{1}$ e da hereditariedade genética de Gregor Mendel ${ }^{2}$, muitos avanços foram realizados no entendimento e no acúmulo de evidências da evolução dos seres vivos. ${ }^{3}$ Hoje podemos considerar a evolução em uma base conceitual praticamente matemática, com leis gerais que vão além da construção dos seres vivos. Na verdade, a palavra 'evolução' pode ser usada para se referir a uma grande variedade de ideias e, em particular, quando falamos atualmente de evolução na biologia, estamos nos referindo a um processo bem definido que pode ser entendido de forma precisa. ${ }^{4,5}$ Esta evolução, de forma geral, se caracteriza como o acúmulo de pequenas variações ao longo das gerações de populações de elementos auto 
replicantes seguido de uma seleção de indivíduos baseada nas pressões do ambiente em que se inserem.

Na biologia, o elemento auto replicante (replicador) que é alvo da evolução e parte integrante de todos os seres vivos é o material genético, os genes que são as unidades capazes de produzir a si mesmas, usando-se de mecanismos bioquímicos. A ocorrência de pequenas variações nesta replicação se dá pela mutação a que os replicadores estão sujeitos ao reproduzir. Esta mutação decorre de erros de execução da replicação, podendo se manifestar de vários modos, possibilitando ao replicador criar em uma reprodução um replicador diferente vindo de um conjunto de replicadores quase idênticos ao anterior, diferenciando-se apenas na porção atingida pela mutação (ou seja, a cada mutação, existe a possibilidade de se criar um replicador novo dentre um conjunto de replicadores acessíveis).

Uma população de replicadores se insere em um ambiente com recursos e espaço finitos, o que os pressiona a competir pela "sobrevivência", ou seja, para obter recursos suficientes a ponto de conseguir se reproduzir com sucesso, produzindo uma nova geração de replicadores que vão propagar as características do replicador que obteve esse sucesso. Essa competição, que impõe a propagação das características do replicador mais apto a obter os recursos pertinentes, gera uma escala de aptidão, denotando a capacidade reprodutiva dos replicadores (em inglês, fitness). Este mecanismo de classificação por aptidão gerada por competição que determina quais replicadores atingem a próxima geração (ou em quais frequências eles atingem) é chamado de seleção natural. Notamos que a seleção natural age sobre os replicadores, então a evolução caminha no sentido de sempre beneficiar somente o replicador em si, por isso estes são vistos como 'egoístas' ${ }^{6}$ (pois beneficiar a si mesmo representa sobrevivência e, portanto, permanência).

Mas ao longo da história evolutiva dos seres vivos, a seleção natural em combinação com a mutação e as características do meio ambiente em que os seres evoluíram permitiram a criação de diversas ferramentas muito eficientes na manutenção da capacidade reprodutiva. Dentre elas, vemos o aparecimento de células especializadas que guardam o material genético (células eucarióticas), reprodução sexuada, seres multicelulares, organização de seres em grupos e sociedades, etc. (inclusive o próprio material genético também pode ser visto já como uma 
ferramenta eficiente de manutenção de capacidade reprodutiva, tendo evoluído a partir de moléculas replicadoras mais primitivas).

Devemos perceber que, quando dizemos que uma característica mais eficiente evoluiu de uma menos eficiente, estamos nos referindo à eficiência local desta característica, sabendo que a eficiência reprodutiva é dependente do próprio ambiente (ou seja, não há a possibilidade de haver um sentido absoluto para a evolução). Diversas características adquiridas com a evolução devem sofrer vários ajustes ou até mesmo ser abandonadas ao longo das gerações. Outra observação é que cada variação capaz de gerar uma nova espécie de seres cria uma ramificação na história evolutiva daquela espécie que indica a coexistência da espécie antiga e da nova. E, a partir daí, a espécie antiga vai ter seus próprios meios de manutenção da capacidade reprodutiva com a passagem do tempo (ou seja, o acúmulo de variações e o surgimento de novas espécies somente causam uma alteração no meio ambiente sem se relacionar diretamente com a possível extinção dos indivíduos que não sofreram dadas mutações). Desta forma vai sendo criada ao longo do tempo uma história evolutiva repleta de ramificações, contendo um grande conjunto de seres diferentes que coexistem, nos mesmos ambientes ou em diferentes ambientes, cada um caminhando sua própria direção evolutiva, estando em um grau maior ou menor de complexidade, dependendo unicamente de sua capacidade reprodutiva para obter sucesso.

Essas ferramentas mais complexas de manutenção de capacidade reprodutiva surgem em saltos na evolução ${ }^{7}$, compreendidos como transições mais importantes da história evolutiva, onde os indivíduos em evolução aproveitam uma janela de condições favoráveis que permitem o acesso a estes saltos. Isso sugere uma seleção em vários níveis, extrapolando o benefício do replicador para se preocupar com o benefício de estruturas envolvendo o replicador. Claro que isto só acontece quando a pressão seletiva em outros níveis é maior que a pressão sobre o replicador; este nunca deixa de ser 'egoísta', apenas se rende à influência indireta de outras estruturas. Sem as dadas condições, a conquista de muitas destas ferramentas não seria possível, pois seu processo de construção resulta em perda local da capacidade reprodutiva. São nestas condições que o mecanismo da cooperação, por exemplo, se torna interessante. ${ }^{8}$

Em resumo, temos que a evolução é um processo resultante de replicadores se reproduzindo, 
sujeitos à mutação, em ambientes que geram pressão seletiva por competição por recursos (resultando em um acúmulo de pequenas variações). Esta evolução, a longo prazo, pode fazer surgirem estruturas ricas em complexidade que servem como ferramentas das mais variadas formas que atuam na manutenção e na eficiência do processo evolutivo; vemos muitas destas estruturas desempenhando papéis fundamentais na organização dos seres vivos atualmente.

\subsection{Cooperação}

Um dos mecanismos que servem de suporte à manutenção da capacidade reprodutiva dos replicadores e também à criação de maior complexidade é a cooperação ${ }^{9}$ entre os replicadores e também entre estruturas maiores produzidas por eles, como as próprias células e os indivíduos multi-celulares (os seres vivos no geral). Podemos observar que as ferramentas evolutivas mencionadas (como seres multicelulares, reprodução sexuada e a própria célula eucariótica) dependem da cooperação em algum nível, seja a cooperação entre diferentes seres vivos ou a cooperação entre os próprios replicadores. Esta cooperação pode ser entendida tanto como uma forma de acordo comportamental (no caso da reprodução sexuada) quanto como algo mais sólido, como a cooperação vitalícia de células formando organismos multicelulares ou mesmo simbioses entre diferentes organismos gerando estruturas mais complexas (como o caso das mitocôndrias).

Quando observamos diferentes indivíduos cooperando, de forma que um executa uma ação que resulta em um benefício para o outro, mutuamente, podemos entender que não há uma contradição com os princípios egoístas dos replicadores. Um replicador pode estar buscando seu próprio benefício e com isso acabar ajudando outro indivíduo, de forma colateral. Embora isto seja possível, muitas formas de cooperação envolvem uma perda de recursos ou capacidade reprodutiva (como o que entendemos por altruísmo, quando especificamente o seu ato de ajudar implica em prejuízo a você) ou necessitam de uma espécie de acordo para funcionar, resultando em uma grande exposição à exploração e também uma necessidade de algum tipo de comunicação.

O entendimento destes processos aos olhos da evolução não é simples, a escolha pela cooperação na maioria das vezes parece arriscada demais para ser considerada pelos replicadores 
e ainda muitos atos de cooperação parecem não fazer qualquer sentido, pois o que vemos é um indivíduo que age de forma a diminuir sua capacidade reprodutiva enquanto aumenta a de outro. Por isso, o problema do entendimento da cooperação aos olhos da evolução está em grande evidência na biologia, atualmente. Nós precisamos construir argumentos e evidências de que a cooperação em última instância resulta em um aumento do sucesso reprodutivo dos indivíduos envolvidos, em todas as suas formas, pois essa é a única maneira de conciliá-la com os mecanismos da evolução. Também precisamos entender como a cooperação pode ser vantajosa em todas as suas etapas, pois a motivação para qualquer esforço dos replicadores deve ser o sucesso reprodutivo; eles não são capazes de 'planejar'.

A cooperação existe de diferentes formas entre os seres vivos, tanto entre indivíduos de uma mesma espécie quanto entre indivíduos de diferentes espécies. Uma forma comum de cooperação, já bastante entendida pelos biólogos, é a cooperação por parentesco, em que os animais podem até se sacrificar por sua prole ou por seus familiares em geral. ${ }^{10}$ É bastante compreensível que os animais se interessem em reconhecer e proteger aqueles que compartilham grande parte de sua identidade genética; apesar de um indivíduo poder arriscar sua capacidade reprodutiva enquanto indivíduo, o efeito do processo evolutivo é proteger o replicador, então um ato altruísta neste cenário pode significar simplesmente a manutenção do sucesso genético daquele indivíduo. Uma mãe que se sacrifica pelos seus filhos tem mais sucesso em sua transmissão genética do que uma mãe que não faz isso.

Por outro lado, o que poderia beneficiar alguém que se coloca em perigo para salvar um desconhecido, ou um indivíduo de outra espécie? Estas coisas acontecem e, particularmente, os seres humanos possuem mecanismos que os impelem a proteger os outros, mesmo que sejam desconhecidos, de forma a vermos nossa história repleta de cooperação e altruísmo. As origens das sociedades humanas são fundamentadas em vários níveis de cooperação entre indivíduos sem parentesco. ${ }^{11}$

Uma grande variedade de sistemas de cooperação entre os seres vivos pode ser entendida como uma forma de reciprocidade. ${ }^{12} \mathrm{Um}$ indivíduo ajuda o outro promovendo um contexto que de alguma forma fará com que ele seja ajudado no futuro. A natureza é repleta de casos de simbiose, mutualismo e diversas formas de acordos em que os animais continuam ajudando 
porque também estão sendo beneficiados com a ajuda de alguém. Mas como evitar que o acordo seja quebrado por uma investida exploratória? Podemos pensar que, se alguém quebra um acordo com você, é só quebrar o acordo de volta, impedindo que você seja continuamente explorado. Mas devemos levar em consideração que, quanto mais voltamos na história evolutiva, menos capacidade de planejamento e percepção está disponível aos seres, muitas vezes não foi possível simplesmente mudar de ideia em relação a algo.

Muito já foi estudado a respeito da reciprocidade direta ${ }^{13-15}$, que naturalmente é a forma de ajudar um indivíduo esperando a colaboração de volta, deste mesmo indivíduo. Esta circunstância é comum em ambientes onde a interação com os mesmos seres é constante, repetida. A cooperação ocorre por meio de uma crescente proximidade entre os indivíduos. É fácil entender a motivação egoísta da reciprocidade direta, uma vez que há a percepção de que se pode 'usar' o outro para obter um ganho maior; atualmente também entendemos bem as estratégias possíveis para fixar a cooperação e evitar a exploração nesta circunstância.

Porém, ao tentarmos entender as bases da evolução humana, tanto genética quanto sóciocultural, notamos que nós dominamos estruturas que permitem cooperação segura mesmo com indivíduos desconhecidos, com quem nunca interagimos antes. A quantidade de pessoas vivendo harmonicamente nas sociedades humanas é insustentável apenas com o benefício da reciprocidade direta. Nós construímos uma forma de cooperação, exclusiva a nós, em que ajudamos alguém em perspectiva da manutenção de uma ordem social que permite que uma terceira pessoa nos ajude no futuro sem nos conhecer. Esta é a cooperação por reciprocidade indireta, o foco do estudo aqui desenvolvido.

\subsection{Reciprocidade indireta}

Por meio da reciprocidade indireta, você coopera com outro indivíduo, até mesmo em uma interação única, sem necessariamente esperar algo em troca daquele indivíduo, mas de forma que existam observadores desta interação. Estes observadores podem tanto confiar em você e aceitar uma cooperação com você em interações futuras quanto espalhar a informação de que você é confiável (também o indivíduo que foi alvo de sua cooperação pode espalhar essa informação), alertando uma população sobre sua atitude, construindo sua reputação. 
Estes outros indivíduos envolvidos nesta interação, além de você, também podem se sentir incentivados a fazer o que você fez. Especificamente, um indivíduo A coopera com o indivíduo $B$, aumentando as chances deste cooperar com outro indivíduo $C$ ou de um outro indivíduo $D$ cooperar com você.

Vemos que esta construção de reputação exige uma grande capacidade de organização social; é preciso ter alguma comunicação eficiente desenvolvida, grande capacidade de julgamento e percepção, etc. Os requisitos cognitivos do sistema de reciprocidade indireta presente nas sociedades humanas fizeram com que este sistema fosse permitido pela e também ter motivado a evolução das nossas capacidades cognitivas e de interação social que nos fizeram humanos, como nos conhecemos (funcionando como um sistema que se auto alimenta). ${ }^{16}$ Experimentos mostram uma grande tendência dos seres humanos a devolver tanto atos de bondade quanto atos de maldade praticados pelos outros ${ }^{17,18}$, mesmo que não tenham envolvido eles próprios. Também vemos isto constantemente no dia-a-dia.

A constituição genética, que constrói o cérebro humano, toda a base fisiológica na qual os processos sócio-culturais agem para nos transformar (fazendo os seres civilizados que somos hoje), é praticamente a mesma das sociedades primitivas. ${ }^{19}$ Entender a origem evolutiva de nossos sistemas de cooperação nas sociedades primitivas é entender nossa tendência físiológica atual para a cooperação. A reciprocidade indireta exerce um papel fundamental nos últimos passos da nossa evolução e na construção destas sociedades primitivas, que nos trouxeram aos dias atuais. Os instintos de retribuição coletiva, de empatia, vingança e generosidade são provavelmente os mesmos daqueles que ajudaram a moldar os primórdios do nosso sistema de cooperação.

Hoje vemos sistemas de reputação e interações com desconhecidos funcionando em uma escala global, principalmente em ambientes virtuais. Mas como isto funcionava em sociedades primitivas? Com a comunicação ainda muito menos eficiente e os sistemas de estabelecimento de reputações muito mais falhos, a cooperação teve que vencer a exploração, que tem um trabalho mais fácil, estabelecendo-se em meio às falhas dos cooperadores em identificar os mal intencionados e diferenciá-los dos seus semelhantes. Sabemos que, em um sistema de cooperação, aquele que se beneficia sem fazer a sua parte acaba tendo mais sucesso que 
os outros. Na verdade, a presença de exploradores pode ter gerado uma pressão seletiva para o desenvolvimento da retribuição e consequentemente da punição, fortalecendo sistemas como a reciprocidade indireta. Mas a cooperação teve que ser forte o suficiente para não ser completamente colapsada por eles, antes de mais nada.

A reciprocidade indireta está relacionada com a origem de sistemas morais, algo também universal em culturas humanas. O controle de reputações, o julgamento da população, depende de normas reguladoras que transformam atitudes em conceitos para rotular os indivíduos. ${ }^{11}$ Entendemos muito de como estes sistemas funcionam, mas precisamos esclarecer os passos que permitiram sua origem. De alguma forma, versões primitivas e incompletas destes sistemas foram suficientes para vencer o impulso por não cooperar.

Diversos trabalhos experimentais ${ }^{20-24}$ reforçam os conceitos presentes na teoria de reciprocidade indireta, revelando a compatibilidade entre as atitudes dos seres humanos e as ideias evolutivas que sustentam o conceito e a evolução da cooperação em nosso comportamento. Os avanços teóricos têm por objetivo desvendar as condições em que estes sistemas surgiram e como foram capazes de se fixar e se tornar eficientes.

Todo este contexto sugere a proposta de um tratamento de dinâmica populacional a estas questões de interação entre indivíduos em uma população com evolução temporal através de gerações. Com o crescente e bem sucedido tratamento analítico da reciprocidade direta, biólogos teóricos, físicos e matemáticos se voltaram à sistematização da reciprocidade indireta. Com um artigo de $1998^{25}$, K. Sigmund e M. Nowak introduziram um modelo para o tratamento da reciprocidade indireta baseado em uma dinâmica populacional modelada na EGT, seguindo os passos da reciprocidade direta e toda a abordagem dos problemas de seleção dependente de frequência, existente desde o surgimento da EGT.

\subsection{Teoria dos jogos evolucionária}

Na matemática, a teoria dos jogos representa o estudo de modelos baseados em interações entre indivíduos que seguem estratégias em função de obter um ganho a elas relacionado. É um tratamento da área de teorias de tomada de decisão. Nos jogos (como são chamadas as interações dotadas de regras a que as estratégias devem se submeter), os indivíduos estabe- 
lecem sequências de decisões, as estratégias, cujo sucesso depende das decisões dos outros envolvidos. As ideias da teoria dos jogos foram amplamente desenvolvidas por J. von Neumann e O. Morgenstern. ${ }^{26}$ Atualmente, o mais conhecido exemplo de jogo, utilizado para o tratamento de diversos tipos de situações é o dilema do prisioneiro (inclusive, é principalmente nesta interação que se baseiam os modelos de reciprocidade). ${ }^{27}$

Basicamente, as estratégias adotadas pelos indivíduos conferem a eles no final do jogo um ganho ou recompensa, denominado em inglês como payoff, de forma que a estratégia mais bem posicionada no jogo seja aquela que resulta em um maior payoff. A tabela com os diferentes resultados de payoff para cada interação entre as estratégias é chamada de matriz de payoff e caracteriza os possíveis resultados do jogo. A teoria dos jogos se preocupa em especificar os diferentes equilíbrios resultantes de escolhas otimizadas de estratégias por todos os jogadores.

A teoria dos jogos foi rapidamente utilizada em diversas aplicações, principalmente na economia $^{28}$ e na biologia teórica. ${ }^{4,29}$ Sua capacidade de sistematizar complexas interações envolvendo disputa e cooperação estabelece grande eficiência na resolução de problemas de conflitos de interesses. Na biologia teórica, suas aplicações no tratamento de dinâmicas de populações descrevendo a atuação evolucionária geraram o estabelecimento da EGT.

Em 1973, através de um artigo publicado por J. M. Smith e G. R. Price ${ }^{30}$, as bases da EGT começaram a se solidificar com um problema de conflito entre indivíduos de uma mesma espécie de animais, envolvendo rituais de guerra relacionados ao acasalamento. Os autores utilizaram os conceitos de teoria de jogos para construir uma matriz de payoff tomando como estratégias os diferentes comportamentos dos animais e encontrar equilíbrios correspondentes ao que se observa na natureza. A EGT foi sendo melhor desenvolvida em trabalhos subsequentes. ${ }^{31}$ Hoje em dia, o desenvolvimento da EGT e da dinâmica de populações se fundem na chamada dinâmica evolucionária. ${ }^{32}$

Na EGT, o payoff de cada jogador, que é o ganho obtido com o jogo, é traduzido em capacidade reprodutiva (fitness). O fitness é então uma medida de replicação e permanência de uma estratégia. Sabemos que uma estratégia é composta da especificação das atitudes de jogadores. O modelo de jogos é uma ferramenta capaz de simular processos dinâmicos de seleção dependente de frequência, ou seja, em sistemas em que a capacidade reprodutiva 
depende das frequências de cada estratégia adotada na população. Isso é algo natural em um jogo, pois é comum que o sucesso de uma atitude dependa das atitudes dos outros jogadores; vimos que os jogos são baseados nessa interatividade.

J. M. Smith cunhou o termo estratégia evolutivamente estável (em inglês, evolutionary stable strategy, ou ESS) ${ }^{33}$ para se referir a um conjunto de estratégias resistente à invasão de outras estratégias em um dado jogo. Portanto, a estratégia que é ESS possui um payoff maior que todas as outras na situação em que esta estratégia domina a população, de forma que a seleção nunca favoreça um mutante de outra estratégia (o payoff de um mutante também pode ser igual ao da estratégia dominante; neste caso, esta é uma ESS se a interação entre dois mutantes da nova estratégia resultar em um menor payoff que a interação do mutante com a estratégia dominante); ou seja, a ESS é a melhor resposta para ela mesma. Uma ESS é um caso particular do equilíbrio de $\mathrm{Nash}^{34}$, um importante conceito de teoria dos jogos que indica a seguinte propriedade: se todos os jogadores jogam uma estratégia que é equilíbrio de Nash, então nenhum deles aumenta seu payoff ao trocar de estratégia (este conceito serve para identificar pontos de equilíbrio de matrizes de payoff).

A modelagem de um jogo evolucionário se dá em dois passos principais. Primeiro, escoIhemos as possíveis estratégias e calculamos o payoff associado a cada estratégia em dada interação, construindo uma matriz de payoff. As interações entre os indivíduos são dadas de forma aleatória. Para o caso de interações repetidas em uma única geração, somamos os payoffs de cada interação para os indivíduos de forma a no fim da geração termos as expressões para os payoffs totais de cada estratégia. No segundo passo, aplicamos a evolução através das gerações; no nosso caso, com a equação dos replicadores ${ }^{35}$. Esta equação utiliza o payoff como medida de capacidade reprodutiva (fitness) e promove a evolução temporal das frequências relativas de cada estratégia baseada na diferença entre seu fitness e a média da população,

$$
\dot{x}_{i}=x_{i}\left[f_{i}(x)-\phi(x)\right], \quad \phi(x)=\sum_{j=1}^{n} x_{j} f_{j}(x) .
$$

Na equação, temos que $x_{i}$ é a frequência da i-ésima estratégia e $f_{i}(x)$ é seu fitness calculado no primeiro passo. Com esta equação, podemos obter a dinâmica temporal das estratégias e fazer uma análise de pontos de equilíbrio, buscando, por exemplo, possíveis estratégias que 
são evolutivamente estáveis. Podemos construir a evolução dinâmica através das gerações para qualquer condição inicial da população, sendo a análise de estabilidade e os pontos de equilíbrio independentes de uma condição inicial. As estratégias bem sucedidas tomam conta da população enquanto as mal sucedidas vão sendo extintas. Podemos notar que esta equação modela a seleção natural agindo sobre as estratégias, sendo que os indivíduos nascem com suas estratégias representando a manifestação de seu conteúdo genético; porém, a equação dos replicadores não leva em consideração a mutação. Desta forma, ao analisar a ocorrência de mutação, devemos introduzir a estratégia mutante dentro de uma geração, calculando seu payoff e, a partir daí, considerá-la na equação dos replicadores. No caso do aparecimento de um novo mutante, pode ser feita a análise da chance de que ele consiga dominar a população, através do seu payoff na condição de seu aparecimento na população.

Claro que a abordagem da EGT se extende a uma grande variedade de tratamentos, mas aqui vamos nos restringir ao caso de grandes populações, tratando da dinâmica contínua pela equação dos replicadores, tomando as estratégias representadas por frações contínuas da população. Aqui também sempre consideraremos uma população homogênea, aleatoriamente distribuída. Estas hipóteses diminuem a realidade do modelo, porém possibilitam um tratamento analítico claro, promovendo direções para aperfeiçoamentos e também delineando as principais estruturas da dinâmica real. A partir dos modelos em populações contínuas e aleatoriamente distribuídas, são feitos avanços em populações discretas e estruturadas. Os tratamentos por simulações computacionais também são uma extensão dos avanços analíticos nos modelos simplificados.

O tratamento analítico da reciprocidade direta foi feito utilizando esta base de teoria dos jogos evolucionária, com o desenvolvimento da estratégia tit for tat, de R. Axelrod e W. D. Hamilton. ${ }^{9}$ Os modelos de reciprocidade indireta podem ser vistos como sequenciais ao desenvolvimento da reciprocidade direta. ${ }^{13 ?, 14}$ A diferença fundamental no tratamento se dá no ponto em que a reciprocidade direta trata de rodadas de interações repetidas com um mesmo indivíduo, enquanto a reciprocidade indireta trata de rodadas de interações com diversos indivíduos da população, sem repetição. Esta característica impede que sejam estabelecidos acordos entre os indivíduos que interagem, necessitando da existência dos sistemas de reputa- 
ção e normas sociais. 


\section{Capítulo 2}

\section{Modelos anteriores}

A partir dos desenvolvimentos do capítulo anterior, trabalharemos com o modelo de Nowak e Sigmund para a reciprocidade indireta; veremos um pouco da história e da evolução do modelo para então introduzir a variação de interações opcionais, que é o foco dos resultados deste trabalho. Começando com a apresentação do modelo, mostraremos as primeiras críticas e modificações, até a sistematização das normas sociais, com os resultados que dão as condições para estas normas levarem a cooperação ao nível de ESS. No final do capítulo, descrevemos os resultados do artigo sobre as interações opcionais, que são consequência destes desenvolvimentos e também representam o modelo a ser expandido neste trabalho.

\subsection{Modelo de Nowak e Sigmund}

Em 1998, procurando sistematizar matematicamente avanços no estudo da reciprocidade indireta, M. Nowak e K. Sigmund propuseram um modelo 25,36 de teoria dos jogos semelhante ao já desenvolvido anteriormente para o tratamento da reciprocidade direta. Em seu primeiro artigo, os autores trabalharam com o conceito de reputação chamado image scoring e fizeram simulações computacionais da dinâmica populacional resultante. No segundo artigo, no mesmo ano, formularam um desenvolvimento teórico que apresentaremos a seguir.

Consideramos uma população grande o suficiente para desconsiderarmos a possibilidade de dois indivíduos interagirem repetidamente e para podermos tratar as diferentes estratégias em termos de proporção contínua da população (com variáveis reais). Esta população é fixa ao 
longo de uma geração em que várias rodadas de interação são dadas. Em cada interação, os indivíduos dessa população são separados em pares para interagirem em um jogo onde podem tomar duas ações, a de cooperar e a de explorar o seu companheiro de jogo. Cada jogador tem a escolha de dar ao outro uma quantia $c$ de seu payoff de forma que o outro receba uma quantidade maior $b$; se um jogador escolhe fazer a doação, ele coopera, senão ele explora. A matriz de payoff de cada jogo é, portanto,

$$
\begin{aligned}
& \text { C E } \\
& C\left(\begin{array}{cc}
(b-c) & -c \\
b & 0
\end{array}\right) \text {. }
\end{aligned}
$$

onde a letra $\mathrm{C}$ representa o ato de cooperar e a letra $\mathrm{E}$ de explorar; os elementos da matriz indicam o payoff da ação representada à esquerda frente à ação representada acima. A população é composta por indivíduos divididos em três estratégias. A estratégia All-C, denotada por frequência $x_{1}$, sempre coopera em um jogo. A estratégia All-D, denotada por frequência $x_{2}$, sempre explora. Por último, a estratégia Disc, de frequência $x_{3}$, utiliza um critério de reputação para discriminar quando cooperar com alguém. Esta estratégia é a que se utiliza de reciprocidade indireta em seu curso de ação. Temos $x_{1}+x_{2}+x_{3}=1$. Através do sistema de reputação de image scoring, aqueles indivíduos que cooperaram na rodada anterior recebem o conceito $G$ (good, de boa reputação); aqueles que exploraram na rodada anterior recebem o conceito $B$ (bad, de má reputação). No início de cada geração toda a população tem boa reputação. A estratégia Disc coopera somente com indivíduos $G$. A princípio, os autores consideram um número fixo de rodadas $M$, mas passam a fazer o tratamento, mais realístico, de um número de rodadas estocástico. A cada rodada, existe uma probabilidade $w$ de ocorrência de outra rodada, de forma que o número médio de rodadas seja $M=(1-w)^{-1}$. Acabadas as rodadas, é computado o payoff total da geração que será utilizado como medida de fitness para cada estratégia. A função $g_{n}$ é definida como a fração de jogadores com boa reputação 
na rodada $n$ e, a partir dela, o payoff dos discriminadores pode ser expresso em cada rodada. Desta forma, temos o payoff de um All-C na rodada $n$ dado por

$$
P_{n}^{1}=(b-c)\left(x_{1}+x_{3}\right)-c x_{2} .
$$

Essa expressão pode ser entendida como: um All-C, ao jogar com outro All-C ou um Disc, recebe $(b-c)$ e, ao jogar com um All-D, recebe apenas $-c$, em todas as rodadas. Assim, seu payoff médio na geração é

$$
P_{1}=\frac{-c+b\left(x_{1}+x_{3}\right)}{1-w}
$$

Para um All-D, temos na rodada $n$, que não seja a primeira

$$
P_{2}^{n}=b x_{1}
$$

que quer dizer que seu payoff só se altera (uma quantidade $b$ ) quando explora um All-C. Na primeira rodada, como ainda não adquiriu má reputação, consegue também explorar os Disc obtendo

$$
P_{2}^{1}=b\left(x_{1}+x_{3}\right)
$$

de forma que seu payoff médio da geração seja

$$
P_{2}=\frac{b\left(x_{1}+x_{3}\right)-w b x_{3}}{1-w} .
$$

Para os Disc, temos que, na rodada $n$, a fração deles que tem boa reputação é igual à fração da população que tinha boa reputação na rodada anterior, pois é a proporção de cooperação que eles realizaram e consequentemente a proporção de quem manteve a própria boa reputação. Isso quer dizer que na rodada $n$ a fração de indivíduos Disc que possuem boa reputação é $g_{n-1}$. O payoff de um Disc na rodada $n$ é então dado por

$$
P_{3}^{n}=g_{n-1}\left[-c g_{n}+b\left(x_{1}+x_{3}\right)\right]+\left(1-g_{n-1}\right)\left(-c g_{n}+b x_{1}\right) .
$$




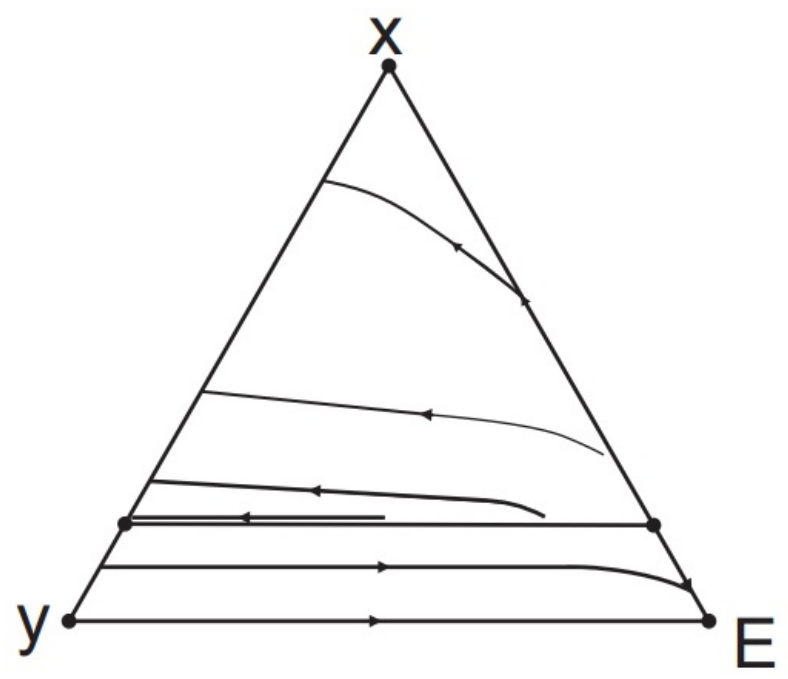

Figura 2.1- Simplex da dinâmica com image scoring. Aqui, a estratégia Disc é representada pela letra $x$, os All-C pela letra $y$ e os All-D pela letra $E$. A lateral $x-y$ representa pontos de equilíbrio neutro entre as duas estratégias, assim vemos que os Disc não formam uma ESS. A linha horizontal próxima à base representa um equilíbrio entre os Disc e os All-D, abaixo desta, os All-D dominam a população. Os All-C podem invadir a população de Disc por deriva até um ponto abaixo desta linha, onde um mutante explorador poderia levar a população ao equilíbrio All-D.

Fonte: NOWAK; SIGMUND. ${ }^{36}$

Ou seja, se um Disc tem boa reputação, coopera com todos os indivíduos de boa reputação, alterando seu payoff em $-c$ e reecbe a cooperação de todos os Disc e All-C, alterando em $b$. Se o Disc possui má reputação, continua cooperando com os mesmos indivíduos, mas recebe cooperação apenas dos All-C. A função $g_{n}$ segue a relação de recorrência $g_{n}=x_{1}+g_{n-1} x_{3}$ com $g_{1}=1$. Após desenvolvidos os cálculos, o payoff médio dos Disc na geração é dado por

$$
P_{3}=-b x_{2}+\frac{(b-c)\left(1-w+w x_{1}\right)}{(1-w)\left(1-w x_{3}\right)} .
$$

Para estes valores de payoff, os autores simularam a dinâmica populacional através das gerações com a equação dos replicadores e, em sua análise, verificaram que a estratégia a favor da reciprocidade indireta, Disc, não constitui uma ESS. Mesmo tendo a capacidade de extinguir os All-D e manter a cooperação por um tempo, a população de Disc pode ser invadida por deriva pelos All-C, os cooperadores incondicionais, que numa população sem AllD, não possuem desvantagens evolutivas em relação aos discriminadores (aqui, falamos em invasão por deriva em um modelo de população infinita, mas entendendo que o limite é uma simplificação modelando uma população finita, sujeita aos efeitos de deriva). Os resultados mostram que, abaixo de um valor crítico para $x_{3}$, os exploradores podem invadir a população 
de discriminadores e cooperadores incondicionais e tomar o controle da população, levando à extinção as outras duas estratégias (os All-D sempre constituem uma ESS). Na Fig. 2.1, representamos um simplex com a dinâmica entre as estratégias (um simplex é um conjunto de pontos cujas coordenadas são não negativas e somam um; no caso de três coordenadas, cada vértice representa a população dominada por uma delas, as outras duas estão extintas, e cada lateral representa a população tendo a estratégia do vértice oposto extinta; O interior do simplex mostra a dinâmica entre as três estratégias).

\subsection{Modificações no modelo de Nowak e Sigmund}

Várias críticas e modificações foram feitas ao modelo de Nowak e Sigmund de $1998 .{ }^{37}$ A ineficiência e falta de realidade do endereçamento de reputação por image scoring logo foi evidenciada. Um outro tipo de endereçamento, mais eficiente e mais realista, chamado stan$\operatorname{ding}^{38,39}$, já havia sido considerado mesmo por Nowak e Sigmund em seu artigo ${ }^{36}$, mas não foi desenvolvido por eles. Segundo o standing, um indivíduo que explora outro com má reputação não altera sua boa reputação para má, como acontece no image scoring, ou seja, o indivíduo não passa de $\mathrm{G}$ para B. Funciona como uma forma de implementar a exploração justificada como retaliação, onde alguém não se prejudica por punir um explorador ou até mesmo se defender de uma exploração (mais plausível em um modelo em que explorar não significa necessariamente retirar algo do outro, mas apenas se recusar a cooperar).

O endereçamento por standing confere maior chance de sucesso aos discriminadores, mostrando que estes podem se tornar uma ESS em um ambiente onde há erros associados ao ato de cooperar. Se considerarmos que o erro é um elemento comum na história da evolução (de fato, os erros de execução fazem parte da base de nossa história evolutiva), podemos implementar esta interação associando uma chance $\alpha<1$ de que um indivíduo consiga executar a cooperação quando tem a intenção de cooperar. A existência do erro de execução favorece os discriminadores que seguem a reputação por standing em relação aos que seguem o image scoring, pois um erro não gera uma cadeia de explorações em uma população dominada por eles. Ou seja, na ocorrência de erros, o standing aumenta as condições da estratégia Disc ser uma melhor resposta para ela mesma. 
Diversos trabalhos organizaram uma crescente formalização dos mecanismos da reciprocidade indireta a partir do modelo de Nowak e Sigmund de $1998 .{ }^{40-42}$ O endereçamento de reputações foi denominado norma social e em conjunto com as estratégias dos jogadores constitui a dinâmica de reputação. ${ }^{43} \mathrm{~A}$ dinâmica de reputação foi extensamente analisada ${ }^{44-46} \mathrm{e}$ os pesquisadores buscaram encontrar quais conjuntos de estratégias e normas sociais favoreciam a manutenção da cooperação via reciprocidade indireta e suas interpretações sociais e cognitivas. ${ }^{47} \mathrm{~A}$ dinâmica de reputações rotula a reputação a ser dada a um jogador por $d(i, j, X)$, dependente da reputação do próprio jogador $i$, da reputação do outro jogador $j$ e da escolha de ação do jogador $X$ (cooperar ou explorar); portanto, se um jogador com boa reputação $(i=G)$ joga com outro de má reputação $(j=B)$ e coopera $(X=C)$, sua nova reputação será $d(G, B, C)$, que pode ser tanto $G$ quando $B$, a depender da norma social. As escolhas dos jogadores podem ser denotadas pelo valor $p(i, j)$, de forma que cada estratégia seja definida pela especificação de um valor para $p$ ( $C$ ou $D$ para cooperação e exploração) para cada entrada $(i, j)$.

Se considerarmos toda a liberdade para a construção de uma norma social, a cada jogo, vemos que são possíveis 4 configurações de reputação dos dois jogadores ( $G G, G B, B G$ e $B B)$ e 2 ações para o jogador a que estamos observando (cooperar e explorar). Para cada um dos 8 cenários, a norma social deve ter uma resposta para a reputação do jogador observado, que pode ser boa ou ruim $(G$ ou $B)$. Assim, são $2^{8}=256$ possibilidades para normas sociais. Além disso, são $2^{4}=16$ possibilidades de estratégias, devendo escolher entre cooperar e explorar em cada uma das 4 configurações de reputação. Se definirmos a estratégia como $\{p\}=\{p(G G), p(G B), p(B G), p(B B)\}$, temos All-C representado por $\{p\}=\{C, C, C, C\}$, All-D por $\{p\}=\{D, D, D, D\}$ e Disc por $\{p\}=\{C, D, C, D\}$.

De todas as 4096 possiilidades de normas $\{d\}$, apenas 8 delas são capazes de sustentar a cooperação como uma ESS diante da interação com todas as possíveis estratégias (chamados de leading eight). Ou seja, segundo a norma social $\{d\}$, existe uma estratégia discriminatória $\{p\}$ que é a melhor resposta contra ela mesma, dentre todas as possíveis. Representamos as características de todas essas dinâmicas capazes de sustentar a cooperação na Fig. 2.2. Vemos que todas possuem as seguintes características: 


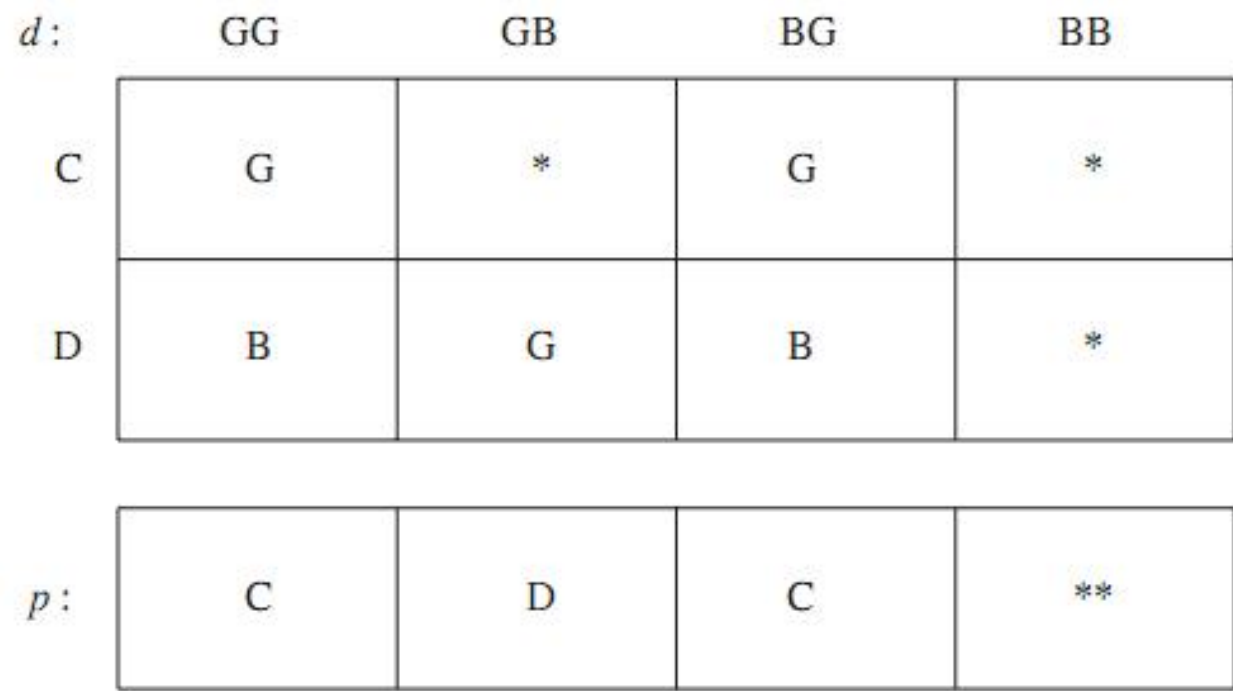

Figura 2.2- As leading eight. A primeira tabela resume as características das leading eight. $\mathrm{O}$ endereçamento de reputações $d$ é lido da seguinte forma: as quatro colunas representam as possibilidades de reputações do jogador em questão e do outro jogador, respectivamente. A ação do jogador em questão é mostrada no lado esquerdo da tabela. A tabela mostra a reputação endereçada ao jogador em questão por sua atitude, os asteriscos dizem que qualquer endereçamento é suficiente (os três asteriscos fazem com que sejam oito formas, logo, as leading eight. A segunda tabela mostra a atitude esperada pela estratégia dos discriminadores $p$, os asteriscos também representam uma escolha inespecificada, ou seja, duas estratégias de discriminadores servem para ser ESS sob estas normas.

Fonte: OHTSUKI; IWASA. ${ }^{44}$

a) $[p(G G)=C ; d(G G, C)=G]$ Se você e o outro jogador são bons, você coopera e mantém a boa reputação (manutenção de cooperação).

b) $[d(G G, D)=B ; d(B G, D)=B]$ Independente da sua reputação, se você explorar alguém bom, você fica mal (identificação de exploradores).

c) $[p(G B)=D ; d(G B, D)=G]$ Se você é bom e o outro jogador é mal, você explora e mantém a boa reputação (punição e justificação da punição, como dizem os autores, ou também, de forma mais realista, prevenção de ser explorado).

d) $[p(B G)=C ; d(B G, C)=G]$ Se você é mal e o outro jogador é bom, você coopera e fica bom (arrependimento e perdão).

As configurações de normas sociais não especificadas podem assumir qualquer valor e a escolha não especificada $p(B B)$ assume um valor específico dependendo da norma social (assume $C$ se $d(B B, C)=G$ e $d(B B, D)=B$ ou $B$ em todos os outros casos), de forma que sejam totalizadas 8 dinâmicas de reputação capazes de manter estável a cooperação, todas com as características mencionadas acima. Vemos que a estratégia Disc e a norma social de 
standing formam uma dinâmica pertencente ao leading eight.

Apesar de normas sociais como o image scoring não serem capazes de proporcionar a estabilidade da cooperação, elas podem causar a ocorrência de cooperação por um período tendo a sua força na sua simplicidade. Apesar do standing e, de forma mais geral, as leading eight serem mais eficientes, estas também representam circunstâncias sociais mais difíceis de serem obtidas em populações primitivas. Vemos que é bem mais difícil controlar a reputação da população para normas mais complexas como as leading eight, os próprios indivíduos devem processar mais dados. Apesar disso, mesmo essas normas não são capazes de promover a estabilidade da cooperação para casos de populações estruturadas, com indivíduos não aleatoriamente distribuídos (através de alguma forma de estrutura espacial), de modo que não sejam todos a possuir a informação sobre as reputações dos outros (algo que por si apresenta um elemento não realístico, ao apostar na total eficiência da transmissão e manutenção da informação através de toda a população). Não se deve ignorar as dificuldades de se estabelecer reputações em um ambiente realista.

Outras modificações ao modelo também foram realizadas, abrangindo aspectos de estrutura e tamanho da população, tais como estudos de reciprocidade indireta em grafos ${ }^{48}$, reputações trinárias ${ }^{49}$ e simulações computacionais ${ }^{50}$, com populações finitas e infinitas. ${ }^{51,52}$ Esta via não será abordada neste trabalho, tendo sua expansão sugerida para futuras pesquisas.

\subsection{Interações opcionais}

Em 2015, M. Nowak e W. Ghang publicaram um artigo ${ }^{53}$ em que dizem que muitas abordagens da reciprocidade indireta utilizam como hipótese a obrigatoriedade das interações. Então eles propõem um modelo de interações opcionais, onde os discriminadores na verdade não jogam com aqueles que possuem má reputação. No modelo do artigo, existe uma população finita com $N$ indivíduos, sendo composta de $i$ cooperadores e $N-i$ exploradores. Novamente, com um número estocástico de rounds em cada geração (considerando o mesmo parâmetro $w$ ) e a mesma matriz de payoff, eles consideram uma dinâmica de reputação onde os exploradores são descobertos após uma exploração com probabilidade $Q$. Se descobertos, nunca mais conseguem interagir com outros cooperadores, pois estes se recusam a participar do jogo quando são 
escolhidos como pares. Os autores fazem os cálculos para a população finita (diferentemente dos anteriores) e descobrem que a cooperação pode ser uma ESS se a desigualdade

$$
\frac{2 Q(b-c)}{N c(1-w)}>1+\frac{2 Q(b-c)}{N c}
$$

for satistfeita. Após cálculos extensos, os autores chegam aos seguintes valores de payoff

$$
F(i)=\operatorname{ch}\left(\frac{B(i-1)}{N-1}-\frac{N-i}{N-1-2 Q \frac{i}{N}+h Q i}\right)
$$

para os cooperadores e

$$
G(i)=\operatorname{ch}\left(\frac{(B+1) i}{N-1-2 Q \frac{i}{N}+h Q i}\right)
$$

para os exploradores, onde temos que $B=\frac{(b-c)}{c}$ e $h=\frac{2}{N(1-w)}$. Uma notável diferença com a abordagem tratada neste artigo é que as rodadas são constituídas de um único jogo, onde apenas um par é selecionado para interagir; a princípio isto, na prática, diminui por um fator $\frac{2}{N}$ a quantidade de rodadas oferecidas. Esperamos que, após um grande número de rodadas, os exploradores se tornem ineficientes em promover a exploração, de forma que os cooperadores são os únicos a acumular payoff. A desigualdade essencialmente mostra o número mínimo de rodadas que seja suficiente para que seja possível que os cooperadores se tornem evolutivamente estáveis.

Depois, os autores analisam a dinâmica da população através das gerações, fazendo $N \rightarrow \infty$ e mantendo $h$ fixo (levando $w$ a um). A frequência de cooperadores se torna $x$ e consequentemente a de exploradores $1-x$. Com isso, obtêm os valores de payoff

$$
F(x)=\operatorname{ch}\left(B x-\frac{1-x}{1+H x}\right)
$$

e

$$
G(x)=\operatorname{ch}\left(\frac{(B+1) x}{1+H x}\right)
$$

com $H=h Q$. Desta forma, a condição para a cooperação poder ser ESS se torna $H B>$ 1. Esta estabilidade da cooperação não é completa, pois ocorre um equilíbrio instável em 
$x^{*}=(B H)^{-1 / 2}$, de forma que, abaixo desta proporção, os exploradores ainda dominam a população de forma estável (ou seja, a dinâmica resulta nas duas estratégias sendo ESS com um equilíbrio instável em um ponto da população mista).

Embora os autores tratem a abordagem de interações opcionais como um novo modelo e realizam os cálculos de uma outra forma, considerando a população finita, vemos que em termos matemáticos não há nada que possa diferenciar a interação dos antigos discriminadores com a não interação dos novos cooperadores opcionais; ambos resultam em inalteração dos payoffs dos envolvidos. Essencialmente, para a dinâmica, temos a mesma estratégia de discriminadores com uma alteração na regra de normas sociais, fazendo que o endereçamento de reputações de um standing seja feito apenas com probabilidade $Q$ (se $Q=1$ temos quase a mesma dinâmica já tratada com a estratégia Disc). Uma outra diferença é que os exploradores só correm o risco de adquirir má reputação após uma real exploração, fazendo com que não interações e interações entre eles não resultem em má reputação (as leading eight não deixavam específica a reputação $d(B B, D)$, mas os cálculos realizados tanto com image scoring quanto com standing a tratavam como $B$ ). Sobre isto, mais será discutido adiante. Em suma, os novos cooperadores opcionais não são eles mesmos diferentes dos antigos Disc, houve mudanças apenas no endereçamento de reputações, mas para uma forma diferente dos cálculos que levaram às leading eight; agora os discriminadores têm uma opção a mais ao interagir com o exploradores, eles não aceitam o jogo (isso contorna a necessidade de restringir as normas sociais no sentido de prevenir a exploração dos discriminadores).

Uma interessante reinterpretação deste modelo pode ser feita da seguinte forma: as interações entre cooperadores e exploradores de má reputação estabelecida serem vistas como um jogo que não ocorre entre eles estão em maior concordância com o fato de os cooperadores intencionarem uma prevenção da exploração ao invés de estarem eles mesmos agindo como exploradores. Esta visão diferencia a ausência de cooperação direcionada a exploradores da exploração em si. E é uma visão mais simples, a princípio mais facilmente realizável do que as mais complexas normas sociais tratadas anteriormente. A introdução do parâmetro $Q$ para a fixação da má reputação pode representar a qualidade da tentativa de a reputação ser espalhada na população; representa o fato de que um explorador muitas vezes pode se manter 
impune após explorar alguém, por vários motivos, principalmente associados à dificuldade de se estabelecer sua reputação para os outros.

Os autores também não testam a efetividade dos discriminadores nesta situação em uma população que contém cooperadores incondicionais. Podemos tomar esta nova visão e refazer os passos anteriores, expandindo este modelo na tentativa de ampliar e simplificar o entendimento sobre o funcionamento e o surgimento da reciprocidade indireta em sociedades humanas. 



\section{Capítulo 3}

\section{Resultados}

Neste capítulo apresentamos nossos desenvolvimentos analíticos. Aqui, vamos reobter os resultados do artigo que introduz as interações opcionais utilizando os métodos introduzidos em 1998, notando algumas diferenças referentes ao limite para o contínuo. Em seguida, faremos a dinâmica de população introduzindo a estratégia dos cooperadores incondicionais (All-C), mostrando que a presença de cooperadores condicionais pode anular o sucesso dos discriminadores. Com isto em vista, apresentamos um modelo com erros de execução que é capaz de recriar a estabilidade dos discriminadores, mesmo na presença dos All-C. No final do capítulo, apresentamos uma variação do modelo em que os exploradores obtêm má reputação ao interagirem entre si (uma variação proposta no artigo de interações opcionais) e também uma construção simples representativa de aspectos de informação incompleta, uma importante característica para a realidade do modelo ${ }^{54}$ a ser considerada em desenvolvimentos futuros.

\subsection{Resolução da relação $f_{n}=A f_{n-1}+B$}

Em nossos resultados, iremos utilizar com frequência a relação de recorrência

$$
f_{n}=A f_{n-1}+B
$$

com $A$ e $B$ sendo coeficientes constantes de forma que $A \neq 0, A \neq 1$ e $B \neq 0$ e tomando a condição de contorno $f_{1}=C$. Nesta seção, vamos resolvê-la nesta forma geral para utilizar 
sua solução nas seções subsequentes. Existem vários métodos para se resolver uma relação de recorrência; esta relação linear, com coeficientes constantes, é bem simples. Podemos resolvêla apenas substituindo os sucessivos termos um no outro. Mas resolveremos através de um ansatz polinomial, de forma análoga à resolução de equações diferenciais. Podemos observar que

$$
f_{n+1}=A f_{n}+B
$$

de forma que, ao subtrair a primeira expressão da segunda, temos

$$
f_{n+1}-f_{n}=A\left(f_{n}-f_{n-1}\right) .
$$

Esta equação é o mesmo que

$$
f_{n+2}-f_{n+1}=A\left(f_{n+1}-f_{n}\right) .
$$

Agora, se imaginarmos uma função da forma $f_{n}=k p^{n}$, teremos

$$
\begin{gathered}
p^{n+2}-p^{n+1}=A\left(p^{n+1}-p^{n}\right) \Longrightarrow \\
\Longrightarrow p^{2}-p=A(p+1) \\
\therefore p^{2}-(A+1) p+A=0 .
\end{gathered}
$$

Resolvendo a equação do segundo grau, temos duas soluções para $p$; $p=1$ e $p=A$. Assim, temos a forma geral para $f_{n}$,

$$
f_{n}=k_{1}+k_{2} A^{n}
$$

Da condição de contorno, temos que $f_{1}=C$. Como aumentamos a ordem da recorrência ao fazermos com que ficasse homogênea, devemos substituir $f_{2}$ na expressão original, ficando com $f_{2}=A C+B$. Com isto, temos um sistema para $k_{1}$ e $k_{2}$, 


$$
\begin{gathered}
C=k_{1}+A k_{2} ; \\
A C+B=k_{1}+A^{2} k_{2} .
\end{gathered}
$$

Este sistema possui a solução

$$
k_{1}=\frac{-B}{(A-1)}
$$

e

$$
k_{2}=\frac{C}{A}+\frac{B}{A(A-1)}
$$

de forma que, substituindo na expressão para $f_{n}$, temos a solução geral

$$
f_{n}=C A^{n-1}+\frac{B\left(A^{n-1}-1\right)}{A-1} .
$$

\subsection{Reobtenção dos payoffs para interações opcionais}

Consideramos uma geração constituída por um número estocástico de rodadas, sendo que, a cada rodada, há uma probabilidade $w$ de que as interações continuem nessa geração. A população é grande o suficiente para que tratemos as estratégias em termos de frações contínuas, os cooperadores $x$ e os exploradores $1-x$. Considerando a matriz de payoff, já considerada do modelo, em que cooperar é perder uma quantidade $c$ para que o outro receba $b>c$ e explorar é deixar de fazer isto. Os cooperadores só aceitam um jogo com exploradores que ainda possuem uma boa reputação e aqui vamos modificar a estrutura das rodadas original, voltando ao formato em que toda a população participa de interações dois a dois em cada uma. Denotamos a fração de jogadores com má reputação na rodada $n$ por $b_{n}$ e que no início todos têm boa reputação $\left(b_{1}=0\right)$. Com isto, temos o payoff médio de cada cooperador na rodada $n$

$$
P_{n}^{C}=(b-c) x-c\left(1-x-b_{n}\right)=(b x-c)+c b_{n} .
$$


Construimos a expressão da seguinte forma: se um cooperador joga com outro cooperador, seu payoff é $(b-c)$ (e a probabilidade de se jogar com outro cooperador é $x$ ). Da mesma forma, se ele jogar com um explorador de boa reputação, seu payoff é $-c$. Com probabilidade $b_{n}$, ele joga com um explorador de má reputação, mas este jogo é negado e não há alteração em seu payoff. Segundo a mesma ideia, temos o payoff de um explorador na rodada $n$

$$
P_{n}^{E}=\frac{\left(1-x-b_{n}\right)}{1-x} b x=b x-\frac{b x}{1-x} b_{n}
$$

Ou seja, o explorador tem boa reputação com probabilidade $\frac{\left(1-x-b_{n}\right)}{1-x}$ e, neste caso, se jogar com um cooperador (probabilidade $x$ ), recebe payoff $b$. Para os outros casos seu payoff não se altera.

A fração de indivíduos com má reputação $b_{n}$ segue a relação de recorrência

$$
b_{n}=b_{n-1}+\left(1-x-b_{n-1}\right) Q x=b_{n-1}(1-Q x)+(1-x) Q x .
$$

Na rodada $n$ esta fração é igual ao que era na rodada $n-1$ mais a fração de indivíduos que adquiriram má reputação nesta rodada, que são aqueles exploradores de má reputação que jogaram com um cooperador, explorando-os, e sendo descobertos com probabilidade $Q$. Resolvemos esta relação na seção anterior, portanto,

$$
b_{n}=(1-x)\left[1-(1-Q x)^{n-1}\right] .
$$

Agora, consideramos a probabilidade de ocorrência da rodada $n$ para calcular o payoff médio dos indivíduos. Uma geração tem $n$ rodadas com probabilidade $(1-w) w^{n-1}$, ou seja, por $n-1$ vezes o jogo prosseguiu, até acabar após a rodada $n$, onde o payoff de um indivíduo é a soma dos payoffs em cada rodada até a número $n$. A média é a soma para todas as $n$ rodadas,

$$
P=\sum_{n=1}^{\infty}(1-w) w^{n-1}\left(\sum_{j=1}^{n} P_{j}\right)=(1-w) \sum_{n=1}^{\infty} \sum_{j=1}^{n} w^{n-1} P_{j} \Longrightarrow
$$




$$
\begin{gathered}
\Longrightarrow P=(1-w) \sum_{j=1}^{\infty} P_{j} \sum_{n=j}^{\infty} w^{n-1}=(1-w) \sum_{j=1}^{\infty} P_{j} w^{j-1} \sum_{n=j}^{\infty} w^{n-j} \\
\therefore P=(1-w) \sum_{j=1}^{\infty} P_{j} w^{j-1}\left(\frac{1}{1-w}\right)=\sum_{n=1}^{\infty} P_{n} w^{n-1} .
\end{gathered}
$$

Aplicando este resultado ao payoff dos cooperadores na rodada $n$, temos

$$
P^{C}=\sum_{n=1}^{\infty} w^{n-1} P_{n}^{C}=(b x-c) \sum_{n=1}^{\infty} w^{n-1}+c \sum_{n=1}^{\infty} b_{n} w^{n-1} .
$$

A primeira soma é novamente a simples soma geométrica, igual a $(1-w)^{-1}$. Vamos resolver a segunda soma,

$$
\begin{gathered}
\sum_{n=1}^{\infty} b_{n} w^{n-1}=(1-x) \sum_{n=1}^{\infty}\left[1-(1-Q x)^{n-1}\right] w^{n-1}= \\
=(1-x) \sum_{n=1}^{\infty} w^{n-1}-(1-x) \sum_{n=1}^{\infty}[w(1-Q x)]^{n-1}=\frac{1-x}{1-w}-\frac{1-x}{1-[w(1-Q x)]} \\
\therefore \sum_{n=1}^{\infty} b_{n} w^{n-1}=\frac{(1-x) w Q x}{(1-w)(1-w+w Q x)} .
\end{gathered}
$$

Desta forma, o payoff médio dos cooperadores resulta em

$$
P^{C}=\frac{b x-c}{1-w}+c \frac{(1-x) w Q x}{(1-w)(1-w+w Q x)}=c k\left(B x-\frac{1-x}{1+(k-1) Q x}\right)
$$

com $k=(1-w)^{-1}$ sendo o número médio de rodadas e $B=\frac{b-c}{c}$ o ganho relativo da cooperação. Fazendo cálculos semelhantes, obtemos para o payoff médio dos exploradores

$$
P^{E}=c k\left(\frac{(B+1) x}{1+(k-1) Q x}\right)
$$

Se compararmos com os resultados obtidos no artigo, expressos na equação (2.3.3), vemos que a diferença entre $h$, o número médio de rodadas jogadas por um indivíduo no modelo do artigo, e $k$, o número médio de rodadas neste caso, é o fator $\frac{2}{N}$. Pelas hipóteses presentes no artigo, o número de jogos oferecidos a um indivíduo tende a zero à medida que a população 
tende a ser infinita, e isto é evitado com as atuais hipóteses. A forma com que os autores levam os parâmetros para o contínuo, mantendo $h$ finito, provoca uma equivalência entre $h$ e $k$, mas este limite se dá ao custo de levar $w$ a 1 . Ou seja, a aproximação do artigo faz com que o número de rodadas tenda a infinito, particularizando o tratamento da dinâmica (e justificando a equivalência, pois, no regime de infinitas rodadas, não importa que em cada rodada não seja toda a população a participar de uma interação). Isto também justifica o único fator diferente entre os payoffs do artigo e os obtidos agora, o $k-1$ que acompanha $Q$ no denominador das duas expressões, em correspondência ao $h$; vemos que, a princípio, deveria ser o fator $k$, mas temos que $k-1=k w$, uma expressão que tende a $k$ no caso em que $w$ tende a 1 . Vemos que a expressão do artigo incorpora essa diferença também como uma aproximação resultante de $w$ tender a 1 . Dito isto, vemos que as expressões reobtidas são equivalentes às expressas no artigo. Se definirmos, neste caso, $H=(k-1) Q$,

$$
P^{C}=c k\left(B x-\frac{1-x}{1+H x}\right)
$$

e

$$
P^{E}=c k\left(\frac{(B+1) x}{1+H x}\right) .
$$

Os gráficos da Fig. 3.1 e da Fig. 3.2 mostram os payoffs obtidos em duas situações, uma delas favorecendo a cooperação com $H B>1$ e outra favorecendo a exploração.

Todas as modificações trabalhadas a seguir seguem esta construção do modelo de interações opcionais, diferentemente do artigo, com todos os indivíduos participando de uma rodada e com $w$ podendo assumir quaquer valor desde zero até um.

\subsection{Dinâmica considerando a estratégia All-C}

Nesta seção, desenvolvemos a dinâmica das três estratégias, analisando a capacidade da estratégia All-C, dos cooperadores incondicionais, de afetar a estabilidade dos cooperadores condicionais, que optam por não jogar com exploradores de má reputação. A estratégia All-C coopera com qualquer indivíduo, sempre. Veremos que a existência de cooperadores incondicionais é 


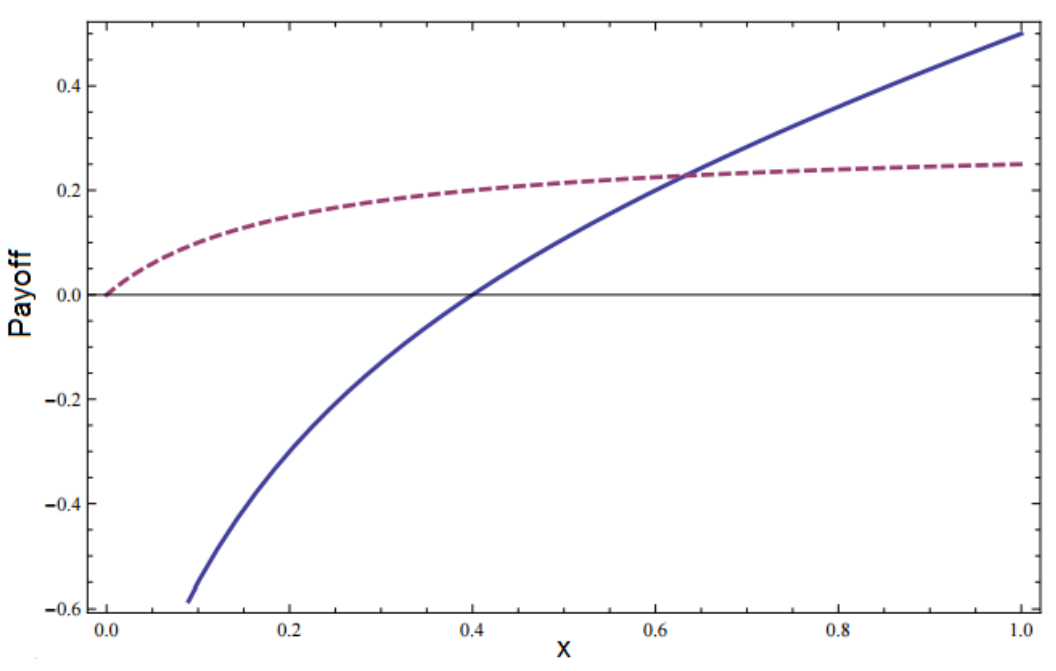

Figura 3.1- Payoffs de interações opcionais para $\mathbf{H B}>\mathbf{1}$. Tomamos os parâmetros $B=0.5, Q=0.5$ e $k=11$, de forma que $H=5$. Assim, $H B=2.5$ e em algum momento o payoff de um cooperador se torna maior que o de um explorador. A curva tracejada representa $P^{E}$ enquanto a outra curva representa $P^{C}$. Reescalamos os payoffs com o fator comum $k c$.

Fonte: Elaborada pelo autor.

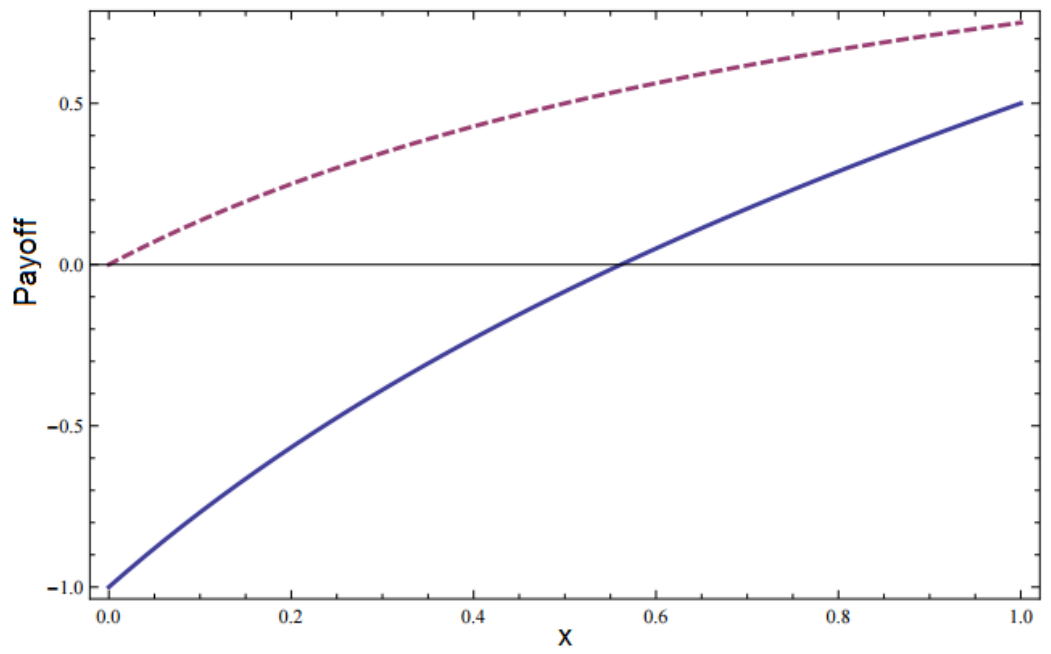

Figura 3.2- Payoffs de interações opcionais para $H B<1$. Tomamos os parâmetros $B=0.5, Q=0.1$ e $k=11$, de forma que $\mathrm{H}=1$. Assim, $\mathrm{HB}=0.5$ e os exploradores dominam em todos os pontos. $\mathrm{A}$ curva tracejada representa $P^{E}$ enquanto a outra curva representa $P^{C}$. Reescalamos os payoffs com o fator comum $k c$.

Fonte: Elaborada pelo autor. 
capaz de desestabilizar o equilíbrio dos discriminadores (cooperadores condicionais), afetando o sucesso da cooperação. Os All-C podem invadir uma população de Disc, possibilitando o domínio da população por exploradores, que se mantêm como ESS.

A partir da abordagem que introduzimos na seção anterior, tomamos a população dividida em cooperadores incondicionais (All-C), com frequência $y$, cooperadores condicionais (Disc), com a estratégia de interações opcionais e frequência $x$, e exploradores (All-D), de frequência $1-x-y$. A fração de indivíduos com má reputação, $b_{n}$, torna-se

$$
\begin{gathered}
b_{n}=b_{n-1}+\left(1-x-y-b_{n-1}\right)(x+y) Q= \\
=b_{n-1}(1-x Q-y Q)+(1-x-y)(x+y) Q=b_{n-1}(1-t Q)+(1-t) t Q,
\end{gathered}
$$

onde definimos a fração de cooperadores $t=x+y$. Consideramos aqui que um indivíduo é passível de ganhar uma má reputação sempre que efetivamente explora alguém, por isso um explorador pode ter má reputação ao jogar tanto com um All-C quanto com um Disc. Esperamos que o ato de exploração (representado por se recusar ajudar um indivíduo que te ajudou, resultando em um payoff $b$ para o explorador) seja o elemento que provoca a injustiça e o espalhamento da má reputação. A solução para esta relação de recorrência (considerando $b_{1}=0$, todos começam com boa reputação), conforme desenvolvido anteriormente, nos dá

$$
b_{n}=(1-t)\left(1-[1-t Q]^{n-1}\right)
$$

Construimos agora as funções de payoff para as três estratégias na rodada $n$. Para a estratégia All-C, temos

$$
P_{n}^{y}=t(b-c)+(1-t)(-c)=t b-c
$$

Ao jogar com outro cooperador, um All-C recebe payoff $(b-c)$ pela cooperação mútua e, ao jogar com um All-D, sempre é explorado e recebe $-c$. Já os exploradores, All-D, recebem

$$
P_{n}^{E}=\frac{\left(1-t-b_{n}\right)}{1-t} t b+\frac{b_{n}}{1-t} y b=t b-\frac{x b b_{n}}{1-t} .
$$


Se o explorador tiver boa reputação, consegue explorar todos os cooperadores, recebendo b. Se tiver má reputação, explora apenas os All-C, recebendo $b$. Do contrário, seu payoff não se altera. Para os cooperadores condicionais, Disc, o payoff é

$$
P_{n}^{x}=t(b-c)+\left(1-t-b_{n-1}\right)(-c)=t b-c+c b_{n}
$$

Novamente, ao jogar com um cooperador, o Disc recebe $(b-c)$ com a cooperação mútua e, ao jogar com um explorador de boa reputação, recebe $-c$. A estratégia Disc não aceita um jogo com um explorador de má reputação. Conforme visto anteriormente, temos os payoffs médios em uma geração

$$
\begin{gathered}
P^{y}=\sum_{n=1}^{\infty} P_{n}^{y} w^{n-1}=\frac{t b-c}{1-w}=k c[t(B+1)-1] \\
P^{x}=\sum_{n=1}^{\infty} P_{n}^{x} w^{n-1}=\frac{t b-c}{1-w}+c \frac{(1-t) w Q t}{(1-w)(1-w[1-Q t])}=k c\left[t(B+1)-1+\frac{t(1-t) H}{1+H t}\right] \\
\mathrm{e} \\
P^{E}=\sum_{n=1}^{\infty} P_{n}^{E} w^{n-1}=\frac{t b}{1-w}-x b \frac{w Q t}{(1-w)(1-w[1-Q t])}=k c \frac{t(B+1)(1+H y)}{1+H t},
\end{gathered}
$$

onde usamos as definições anteriores $k=(1-w)^{-1}, c B=(b-c)$ e $H=(k-1) Q$. Também inserimos o resultado

$$
\sum_{n=1}^{\infty} b_{n} w^{n-1}=\frac{w Q t}{(1-w)(1-w[1-Q t])}
$$

com obtenção análoga à da seção anterior, apenas com $x \rightarrow t$. É fácil ver que a equação dos replicadores é invariante em relação à adição de uma mesma função a todos os payoffs;

$$
\dot{x}_{j}=x_{j}\left[P^{x_{j}}-\sum_{i} x_{i} P^{x_{i}}\right] .
$$

Se fizermos $P^{x_{i}} \rightarrow P^{x_{i}}+P^{\prime}$ para todos os $i$ 


$$
\begin{gathered}
\dot{x}_{j}=x_{j}\left[\left(P^{x_{j}}+P^{\prime}\right)-\sum_{i} x_{i}\left(P^{x_{i}}+P^{\prime}\right)\right]=\dot{x}_{j}=x_{j}\left[P^{x_{j}}+P^{\prime}-\sum_{i} x_{i} P^{x_{i}}-P^{\prime} \sum_{i} x_{i}\right]= \\
=x_{j}\left[P^{x_{j}}+P^{\prime}-\sum_{i} x_{i} P^{x_{i}}-P^{\prime}\right]=x_{j}\left[P^{x_{j}}-\sum_{i} x_{i} P^{x_{i}}\right]
\end{gathered}
$$

Com isto, podemos fazer com que o payoff médio de um explorador seja zero para facilitar a análise. Assim, redefinimos

$$
\begin{gathered}
P^{x}=k c\left[t(B+1)-1+\frac{t(1-t) H}{1+H t}-\frac{t(B+1)(1+H y)}{1+H t}\right]=k c\left[\frac{H t(B x-y)-1}{1+H t}\right], \\
P^{y}=k c\left[t(B+1)-1-\frac{t(B+1)(1+H y)}{1+H t}\right]=k c\left[\frac{H x t(B+1)}{1+H t}-1\right]
\end{gathered}
$$

e

$$
P^{E}=0
$$

Colocando o resultado na equação dos replicadores, construímos a dinâmica da seleção entre as gerações;

$$
\dot{x}=x\left(P^{x}[1-x]-P^{y} y\right)
$$

e

$$
\dot{y}=y\left(P^{y}[1-y]-P^{x} x\right)
$$

Primeiramente, vemos que se $x=1$ e $y=0$, representando a situação onde a população é composta apenas pela estratégia Disc, de cooperadores condicionais, então a dinâmica cessa e a população permanece neste estado infinitamente (vemos nas equações acima que $\dot{x}=\dot{y}=0$ ). O mesmo vale para a população composta somente por All-C ou por All-D. Estes três estados são estados absorventes. Isto é previsível, pois a equação dos replicadores não leva 
em conta a mutação, ou seja, o aparecimento de uma estratégia como descendente de outra. Apesar disso, podemos considerar o que aconteceria caso um mutante aparecesse, por isto analisamos a estabilidade destes pontos de absorção, para verificar se são resistentes à invasão pelo aparecimento de mutantes. Vamos construir um simplex, representando a dinâmica das três estratégias; uma representação gráfica em forma de um triângulo onde cada vértice é um ponto de absorção, contendo somente uma das três estratégias, os lados sendo as linhas de dinâmica onde apenas a estratégia do vértice oposto está extinta e o interior indicando a dinâmica através das gerações com as três estratégias presentes.

Nestes pontos de absorção, a relação entre os valores de payoff das estratégias nos fornece informações sobre sua estabilidade. No ponto de absorção da estratégia All-C, temos $P^{y}=$ $P^{x}=-k c$, portanto essa estratégia sempre vai ser invadida pelos exploradores ou começar a dividir espaço com os Disc por deriva (como dito anteriormente, algo natural enquanto tratamos a população finita como uma aproximação que modela populações finitas).

No ponto de absorção dos All-D, temos os mesmos valores para o payoff dos cooperadores, $-k c$. Neste caso, os exploradores formam uma ESS, não podendo ser invadidos. Temos então que, se a população chegar a este ponto, os exploradores vencem e a cooperação não consegue dominar (apesar de que podemos estudar situações onde mutantes conseguem se fixar na população com certa probabilidade mesmo com desvantagem evolutiva; analisamos este aspecto em outras situações).

Já no ponto dos Disc, temos uma condição para estabilidade. Nesta situação, o payoff dos cooperadores é

$$
P^{x}=P^{y}=k c \frac{H B-1}{1+H} .
$$

Dependendo dos valores de $H$ e $B$, os exploradores podem ou não ter vantagem sobre os cooperadores neste ponto. A condição para $P^{x}>0$ é $H B>1$. Esta é a condição já calculada na seção anterior para a estabilidade da cooperação na ausência dos All-C. Então, se esta condição não se satisfaz, nem é preciso a existência dos All-C para desestabilizar os cooperadores condicionais

Analisemos o comportamento da dinâmica nas três laterais. Começamos com o caso em 
que $y=0$, ou seja, na situação onde não há All-C. Esta é a situação tratada no artigo, cujos resultados foram obtidos neste formalismo na seção anterior. Temos os payoffs

$$
P^{x}=k c \frac{H x^{2} B-1}{1+H x}
$$

e

$$
P^{y}=k c \frac{H x^{2} B-1-H x(1-x)}{1+H x}
$$

Ao igualar $P^{x}$ a zero, teremos um ponto de equilíbrio instável se $H B>1 \mathrm{com}$ a fração de Disc $x^{*}=(H B)^{-1 / 2}$. Portanto, acima deste valor de $x$, a dinâmica tende a levar o sistema a uma população apenas de Disc, extinguindo os exploradores; abaixo deste valor, são os exploradores que dominam a população, de forma que as duas estratégias são ESS. A estratégia vencedora depende da composição inicial da população. O payoff dos All-C é sempre menor que zero para $0 \leq x \leq 1$, portanto os cooperadores incondicionais estão sempre em desvantagem nesta lateral.

Para o caso em que $t=1$, com os exploradores extintos, vemos que os payoffs dos dois tipos de cooperadores se igualam, de forma que independente dos valores de $x$ e $y$, a população se encontra em uma espécie de equilíbrio em que nenhuma das estratégias é favorecida,

$$
P^{x}=P^{y}=k c \frac{H(B x+x-1)-1}{1+H}
$$

Esta é a característica interessante que faz com que os All-C possam atrapalhar a estabilidade dos Disc, sendo capazes de invadir a população de Disc por meio de deriva. Nossa análise inclui encontrar possíveis pontos a partir dos quais o aparecimento de um mutante explorador pode invariavelmente levar a população a um equilíbrio somente de exploradores, como acontece com a estratégia Disc sob a norma de image scoring. Adiante, vamos analisar com mais detalhes o ponto de equilíbrio entre as três estratégias nesta lateral (o ponto onde os valores de payoff acima são nulos).

Para o caso em que $x=0$, podemos observar que $P^{y}=-k c$ enquanto 


$$
P^{x}=-k c \frac{1+H y^{2}}{1+H y}
$$

que são sempre valores negativos (ainda que $P^{x}>P^{y}$ ). Assim, os exploradores sempre têm vantagem sobre os All- $\mathrm{C}$, como pode ser previsto, pois os $\mathrm{All}-\mathrm{C}$ não possuem mecanismos para deixarem de ser explorados. Assim, os Disc podem ter mais chances de invadir a população quanto mais esta é composta por indivíduos All-C, enquanto os exploradores tendem a dominar esta lateral.

Concluimos, então, que nas laterais há apenas um ponto de equilíbrio instável entre as duas estratégias da situação onde $y=0$, além de toda a linha para $t=1$ formar um equilíbrio entre os dois tipos de cooperadores onde não há estratégia favorecida.

Ao igualarmos todos os payoffs, temos a condição $P^{x}=P^{y}=0$, que resulta

$$
t(1-t)=0
$$

e

$$
t(B+1)-\frac{t(B+1)(1+H y)}{1+t H}=1 .
$$

Com este resultado, vemos que não há pontos de equilíbrio no interior do simplex. Ao analisarmos os possíveis pontos das laterais ou mesmo dos vértices onde todos os payoffs podem ser iguais, podemos ter $t=0$ ou $t=1$. Para $t=0$, a segunda igualdade se torna impossível, então este caso não produz resultados. Para o caso em que $t=1$, estamos na linha onde não há exploradores. Aqui, já sabemos que os payoffs dos dois tipos de cooperadores é o mesmo, independentemente dos valores de $x$ e $y$. Mas aqui temos uma situação onde este payoff se anula, tornando-se igual ao dos exploradores. Analisando a segunda igualdade, temos a condição para este equilíbrio

$$
x^{*}=\frac{(1+H)}{H(1+B)}
$$




$$
y^{*}=\frac{(H B-1)}{H(1+B)} .
$$

Este resultado nos indica o ponto a partir do qual a fração de All-C aumenta o payoff dos exploradores de forma que ultrapassem o dos cooperadores condicionais. Assim, se a fração de All-C ultrapassar $y^{*}$ por deriva neutra, um mutante explorador pode levar a população para um equilíbrio de exploradores e, como vimos, esta é uma ESS. Assim, os exploradores são resistentes até mesmo à invasão de qualquer mutante cooperador e essa condição é alcançada pela simples deriva. Para os valores de $x<x^{*}$ o payoff dos Disc (e dos All-C) fica negativo.

Vamos analisar as condições a serem satisfeitas por $H$ e $B$ para que este equilíbrio exista, sabendo que $B>1$. Observamos que a condição para que $x^{*}>y^{*}$ é $2 B+B H>H$, o que sempre ocorre, então este ponto existe com os Disc compondo menos da metade da população. Temos que $0 \leq x^{*} \leq 1$ e o mesmo vale para $y^{*}$. Essas condições, mutuamente satisfeitas, geram o resultado $H B \geq 1$, mas para a igualdade temos $y^{*}=0$ e esse ponto é o ponto em que a estratégia Disc domina a população. Para os casos em que $H B<1$ este ponto não existe. Podemos observar, então, que a forma de evolução desta população através das gerações se divide em dois casos, dependendo de $H B$ ser maior ou menor que 1.

Se $H B<1$, a população só de exploradores forma o único equilíbrio estável e a população sempre tende a este ponto. Como vemos na representação do simplex, as flechas sempre apontam para o vértice dos All-D, a menos da linha onde eles estão extintos, que forma um equilíbrio indiferente entre as duas estratégias cooperadores; porém, mesmo neste equilíbrio, se um mutante explorador aparecer, a dinâmica tende ao vértice dos exploradores, pois o seu payoff é maior mesmo nesta linha.

No caso em que $H B>1$, vemos o aparecimento destes pontos de equilíbrio, mostrando que os cooperadores condicionais são capazes de se fixar na população, mas que o aparecimento de cooperadores incondicionais por deriva é capaz de atingir um limiar a partir do qual o aparecimento de um mutante explorador pode levar, por pressão seletiva, a uma população dominada por exploradores. O payoff de um Disc se iguala ao de um All-D nas laterais do simplex nestes dois pontos, 


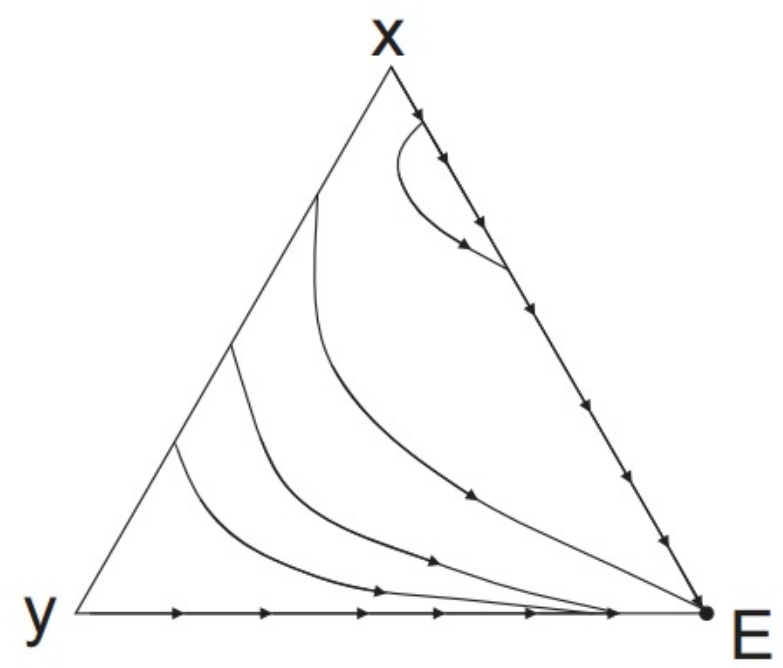

Figura 3.3- Simplex da dinâmica para $\mathrm{HB}<1$. Vemos que os exploradores formam a única ESS da dinâmica e, a partir de qualquer ponto, dominam a população. Não há qualquer chance da cooperação se estabelecer.

Fonte: Elaborada pelo autor.

$$
x_{1}^{*}=\frac{H+1}{H(B+1)}
$$

e

$$
x_{2}^{*}=\frac{1}{\sqrt{H B}} .
$$

O primeiro, na lateral onde os exploradores estão extintos, representa o limiar para a invasão dos exploradores. O segundo, na lateral onde os All-C estão extintos, representa o equilíbrio instável entre os Disc e os All-D. Existe uma linha no interior do simplex que liga estes dois pontos e representa a divisão em que a estratégia Disc tem o mesmo payoff que a estratégia All-D. Abaixo desta linha, os exploradores vencem na dinâmica enquanto acima da linha os cooperadores condicionais que têm maior payoff. Igualando o payoff dos Disc a zero, chegamos à equação desta linha interna

$$
\begin{gathered}
t(B+1)-1+\frac{t(t-1) H}{1+H t}=\frac{(1+H y)(B+1) t}{1+H t} \Longrightarrow \\
\Longrightarrow x^{2} B H-y^{2} H+x y H(B-1)-1=0
\end{gathered}
$$

Nos simplex da Fig. 3.3 e da Fig. 3.4 vemos um esboço da representação gráfica da dinâ- 


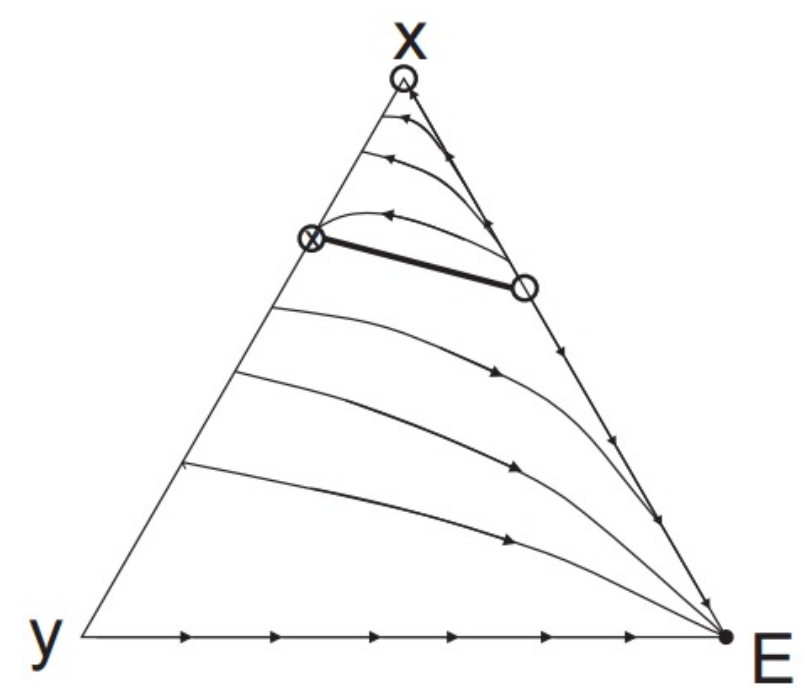

Figura 3.4- Simplex da dinâmica para $H B>1$. Vemos o aparecimento do equilíbrio instável na lateral $x-E$ e o ponto de equilíbrio entre os Disc e os All-D na lateral $x-y$. A linha que liga os dois pontos representa o equilíbrio entre etas duas estratégias, sendo o limiar separando a população em duas partes, abaixo levando ao sucesso da exploração e acima levando ao sucesso da cooperação. A lateral $x-y$ inteira representa um equilíbrio neutro entre os Disc e os All-C, podendo ser percorrida por deriva. Uma população no vértice $x$ eventualmente atinge o limiar por deriva e pode irreversivelmente ser dominada por exploradores.

Fonte: Elaborada pelo autor.

mica obtida nesta seção, para os casos $H B<1$ e $H B>1$. Concluimos aqui que a presença da estratégia All-C, podendo servir como um elo entre os exploradores e os discriminadores, levando em consideração que a cooperação evolui a partir de formas menos complexas, afeta a capacidade dos Disc de se estabilizar na população, invadindo por deriva; mas também destrói a manutenção da cooperação a longo prazo, pela existência de um limiar abaixo do qual o aparecimento de um explorador pode levar a população ao domínio da exploração.

\subsection{Erros de execução na cooperação}

Nesta seção implementamos os importantes erros de execução, representando a falha em cooperar quando se há a intenção de cooperar. Vamos mostrar que, no caso com a presença dos erros, a estratégia dos Disc pode ser uma ESS para o modelo de interações opcionais mesmo na presença da estratégia All-C, pois os erros fazem com que o payoff dos cooperadores incondicionais seja menor do que o dos cooperadores condicionais quando não há exploradores.

Consideramos que um cooperador somente consegue cooperar com probabilidade $\alpha$ sempre que intenciona cooperar. Para o sistema de endereçamento de reputações, um indivíduo 
recebe má reputação sempre que efetivamente explora outro, ou seja, acaba recebendo $b$ como payoff em uma interação (explorar enquanto o outro coopera). Para conseguir um progresso analítico, entretanto, devemos considerar algumas modificações ao modelo de interações opcionais. Com a ocorrência de erros, os cooperadores também vão adquirir más reputações. A estratégia Disc nas interações opcionais não interage com quem tem má reputação, desta forma nunca altera seu payoff quando encontra alguém com má reputação. Aqui, vamos considerar que a estratégia Disc pode receber payoff pela cooperação de outro Disc ou um All-C que esteja com a reputação manchada por um erro. Esta situação ainda pode ser interpretada como de interação opcional, se considerarmos que a ausência de cooperação por parte dos Disc seja diferenciada da exploração de um All-D, interpretando que, apesar do desinteresse de um Disc pela interação, o outro jogador, cooperador, insiste em promover a cooperação. O comportamento do Disc é não arriscar cooperar, é estranho porque essa atitude não se separa da exploração em si, nos cálculos (a exploração se dá a nível de interpretação, pois um explorador não rouba payoff a mais do outro jogador). Adiante, veremos também que, apesar disto poder resultar em uma posição privilegiada dos Disc por não adquirirem má reputação ao efetivamente agirem como exploradores (recusando-se a cooperar, independentemente do motivo), a reputação dos Disc não altera os resultados. Então, este cálculo poderia igualmente significar que, ao invés de interações opcionais, os Disc simplesmente escolhem explorar quem tem má reputação (aproximando-se das interpretações dos modelos anteriores) ou usar o sistema de reputações para não cooperar quando isto é arriscado (como um modelo de 'cooperação opcional' ao invés de interação opcional), podendo ou não ganhar má reputação por isso. De qualquer forma, o desenvolvimento a seguir mostra analiticamente uma condição em que a estratégia Disc constitui uma ESS, mesmo que não seja compreendida como por interações opcionais.

Tomamos $b_{n}$ como a fração de indivíduos All-D com má reputação, $c_{n}$ como a fração de indivíduos Disc com má reputação e $d_{n}$ como a fração de indivíduos All-C com má reputação, todos na rodada $n$. Desta regra para endereçamento de reputações, temos (novamente considerando $x$ como a fração de Disc, $y$ como a de All-C e $(1-x-y$ para os All-D; com $t=x+y$ o número de cooperadores no total) 


$$
b_{n}=b_{n-1}+\left(1-t-b_{n-1}\right) t Q \alpha=b_{n-1}(1-t \alpha Q)+(1-t) t \alpha Q .
$$

Temos que $b_{n}$ é a fração de All-D com má reputação na rodada anterior mais a fração de All-D com boa reputação que interagiu com um cooperador que conseguiu cooperar, sendo descoberto com probabilidade $Q$. Para os Disc,

$$
c_{n}=c_{n-1}+\left(x-c_{n-1}\right)\left(t-c_{n-1}-d_{n-1}\right)(1-\alpha) \alpha Q .
$$

Já $c_{n}$ é esta fração na rodada anterior mais a fração de indivíduos Disc que falharam em cooperar com alguém que conseguiu cooperar com eles (levando em conta que os Disc só tentam cooperar com quem tem boa reputação). A forma de $d_{n}$ é

$$
d_{n}=d_{n-1}+\left(y-d_{n-1}\right) t(1-\alpha) \alpha Q=d_{n-1}(1-t[1-\alpha] \alpha Q+y t(1-\alpha) \alpha Q
$$

Novamente, os All-C que adquirem má reputação na rodada anterior são aqueles de boa reputação que falham em cooperar com um cooperador. Neste endereçamento de reputações, estamos considerando que a falha em cooperar com outro cooperador pode gerar má reputação mesmo que este tenha má reputação, no caso em que ele consegue cooperar de volta (os Disc, que usam as reputações, registram o ato de exploração). Poderíamos construir a reputação de um Disc de outra forma, considerando a escolha por não cooperar com alguém de má reputação como exploração; assim,

$$
c_{n}=c_{n-1}+\left(x-c_{n-1}\right) t(1-\alpha) \alpha Q \text {. }
$$

Os Disc poderiam receber má reputação na interação com qualquer cooperador, não somente aqueles com boa reputação. Não teríamos dificuldades em calcular esta relação de recorrência, mas não faria diferença. Veremos que os payoffs das três estratégias não dependem da reputação dos Disc (se considerássemos o caso em que os Disc não recebem o payoff dos cooperadores com má reputação, deveríamos necessariamente utilizar a outra forma de $c_{n}$ 
e com os payoffs dependendo de sua forma, dificultando o progresso analítico).

Vamos construir os payoffs das três estratégias na rodada $n$, de forma análoga à seção anterior. Para um explorador

$$
P_{n}^{E}=\frac{\left(1-t-b_{n}\right)}{1-t} t \alpha b+\frac{b_{n}}{1-t} y \alpha b=t \alpha b+\frac{x \alpha b}{1-t} b_{n} .
$$

Se o explorador tiver boa reputação, recebe $b$ em cada cooperação bem sucedida, sempre que encontra um cooperador. Se tiver má reputação, só recebe a cooperação dos All-C. Para um cooperador incondicional

$$
P_{n}^{y}=-c \alpha(1-t)+y L+\frac{d_{n}}{y} x \alpha(-c)+\frac{\left(y-d_{n}\right)}{y} x L
$$

com

$$
\begin{gathered}
L=\left([b-c] \alpha^{2}+b \alpha[1-\alpha]-c[1-\alpha] \alpha\right)=\alpha(b-c) ; \\
\therefore P_{n}^{y}=\alpha(t b-c)-\frac{\alpha x b}{y} d_{n}
\end{gathered}
$$

Um All-C sempre quer cooperar. Se encontra um explorador, sempre recebe $-c$ ao conseguir executar a cooperação. Se encontra outro cooperador, recebe o payoff $L$, que representa o payoff de dois cooperadores quando jogam com a intenção de cooperar. Se os dois conseguem, o cooperador em questão recebe $(b-c)$; se somente ele não consegue, recebe $b$; se somente ele consegue, recebe $-c$; se nenhum consegue, ninguém altera seu payoff. Caso o All-C encontre um Disc, se tiver má reputação, somente ele tem intenção de cooperar; se tiver boa reputação, os dois têm intenção de cooperar. Para o payoff de um cooperador condicional,

$$
\begin{gathered}
P_{n}^{x}=\left(1-t-b_{n}\right)(-c \alpha)+\left(y-d_{n}\right) L+d_{n} b \alpha+\frac{c_{n}}{x}\left(x-c_{n}\right)(-c \alpha)+\frac{\left(x-c_{n}\right)}{x}\left(L\left[x-c_{n}\right]+b \alpha c_{n}\right) \\
\therefore P_{n}^{x}=\alpha(t b-c)+\alpha c\left(b_{n}+d_{n}\right)
\end{gathered}
$$

Se o Disc encontra um explorador de boa reputação, aceita jogar e recebe $-c$ se conseguir 
cooperar. Se encontra um All-C de boa reputação, ocorre a situação do payoff $L$. Se encontra um All-C com má reputação, então não aceita cooperar, permitindo que somente o All-C tente cooperar. Na interação com outro Disc, se o Disc em questão possuir má reputação, somente ele tenta cooperar caso o outro tenha boa reputação; se o outro também não tiver, nada acontece. Caso ele possuir boa reputação, somente o outro tenta cooperar se tiver má reputação, ou ocorre a situação descrita com o payoff $L$ caso também tenha boa reputação. Aqui vemos como o desenvolvimento dos termos ocasiona no cancelamento de $c_{n}$, deixando a expressão de $P_{n}^{c}$ bem mais simples e de possível obtenção analítica.

As fraç̃̃es da população $b_{n}$ e $d_{n}$, com as recorrências já resolvidas, ficam, tomando a partir daqui $\beta=1-\alpha$,

$$
b_{n}=(1-t)\left(1-[1-t \alpha Q]^{n-1}\right)
$$

e

$$
d_{n}=y\left(1-[1-t \alpha \beta Q]^{n-1}\right)
$$

Para calcular os payoffs médios ao longo de uma geração, como já visto, é preciso tomar as somas

$$
\begin{gathered}
\sum_{n=1}^{\infty} w^{n-1}=\frac{1}{1-w}, \\
\sum_{n=1}^{\infty} w^{n-1} b_{n}=(1-t) \sum_{n=1}^{\infty} w^{n-1}\left(1-[1-t \alpha Q]^{n-1}\right)=\frac{w(1-t) t \alpha Q}{(1-w)(1-w[1-t \alpha Q])}
\end{gathered}
$$

e

$$
\sum_{n=1}^{\infty} w^{n-1} d_{n}=y \sum_{n=1}^{\infty} w^{n-1}\left(1-[1-t \alpha \beta Q]^{n-1}\right)=\frac{w y t \alpha \beta Q}{(1-w)(1-w[1-t \alpha \beta Q])}
$$

Com isto, calculamos os payoffs médios das três estratégias. Para os All-D 


$$
\begin{gathered}
P^{E}=\sum_{n=1}^{\infty} w^{n-1} P_{n}^{E}=\alpha t b \sum_{n=1}^{\infty} w^{n-1}-\frac{\alpha x b}{1-t} \sum_{n=1}^{\infty} w^{n-1} b_{n} \\
\therefore P^{E}=\alpha\left\{\frac{t b}{1-w}-\frac{x b w t \alpha Q}{(1-w)(1-w[1-t \alpha Q])}\right\}=k c \alpha\left\{\frac{t(B+1)(1+H \alpha y)}{1+H t \alpha)}\right\}
\end{gathered}
$$

onde utilizamos as definições $k=(1-w)^{-1}, B c=(b-c)$ e $H=(k-1) Q$. Para os Disc

$$
\begin{gathered}
P^{x}=\sum_{n=1}^{\infty} w^{n-1} P_{n}^{x}=\alpha(t b-c) \sum_{n=1}^{\infty} w^{n-1}+\alpha c\left[\sum_{n=1}^{\infty} w^{n-1} b_{n}+\sum_{n=1}^{\infty} w^{n-1} d_{n}\right] \Longrightarrow \\
\Longrightarrow P^{x}=\alpha\left\{\frac{t b-c}{1-w}+\frac{c w(1-t) t \alpha Q)}{(1-w)(1-w[1-t \alpha Q])}+\frac{c w y t \alpha \beta Q}{(1-w)(1-w[1-t \alpha \beta Q])}\right\} \\
\therefore P^{x}=k c \alpha\left\{t(B+1)-1+\frac{(1-t) t H \alpha}{1+H t \alpha}+\frac{y \alpha \beta t H}{1+H t \alpha \beta}\right\}
\end{gathered}
$$

E, finalmente, para os All-C

$$
\begin{gathered}
P^{y}=\sum_{n=1}^{\infty} w^{n-1} P_{n}^{y}=\alpha(t b-c) \sum_{n=1}^{\infty} w^{n-1}-\frac{\alpha x b}{y} \sum_{n=1}^{\infty} w^{n-1} d_{n} \Longrightarrow \\
\Longrightarrow P^{y}=\alpha\left\{\frac{t b-c}{1-w}-\frac{w x b \alpha \beta t Q}{(1-w)(1-w[1-t \alpha \beta Q])}\right\} \\
\therefore P^{y}=k c \alpha\left\{t(B+1)-1-\frac{x \alpha \beta t(B+1) H}{1+H t \alpha \beta}\right\}
\end{gathered}
$$

Novamente, vamos explorar o fato da equação dos replicadores ser invariante em relação à adição de uma mesma função em todos os payoffs para levar o payoff dos exploradores a zero. Assim,

$$
\begin{gathered}
P^{x}=k c \alpha\left\{t(B+1)-1+\frac{(1-t) t H \alpha}{1+H t \alpha}+\frac{y \alpha \beta t H}{1+H t \alpha \beta}-\frac{t(B+1)(1+H \alpha y)}{1+H t \alpha)}\right\}, \\
P^{y}=k c \alpha\left\{t(B+1)-1-\frac{x \alpha \beta t(B+1) H}{1+H t \alpha \beta}-\frac{t(B+1)(1+H \alpha y)}{1+H t \alpha)}\right\}
\end{gathered}
$$




$$
P^{E}=0
$$

A dinâmica através das gerações é dada pela equação dos replicadores

$$
\dot{x}=x\left(P^{x}[1-x]-P^{y} y\right)
$$

e

$$
\dot{y}=y\left(P^{y}[1-y]-P^{x} x\right)
$$

Naturalmente, temos que os vértices do simplex são pontos de absorção. Vamos analisar a estabilidade de cada um deles. Começando pelo vértice dos exploradores, com $t=0$,

$$
P^{x}=P^{y}=-k c \alpha .
$$

Com isso podemos ver que os All-D formam uma ESS, como sempre. É interessante notarmos que este é o único ponto onde os payoffs $P^{x}$ e $P^{y}$ são iguais. Ao olharmos para as expressões dos payoffs, podemos concluir que $t=0$ é uma condição necessária para sua igualdade. Para isto, notamos que as frações que compõem estas expressões são todas positivas. Se fizermos $P^{x}=P^{y}$,

$$
\frac{(1-t) t H \alpha}{1+H t \alpha}+\frac{y \alpha \beta t H}{1+H t \alpha \beta}=-\frac{x \alpha \beta t(B+1) H}{1+H t \alpha \beta}
$$

Vemos então que o lado esquerdo é positivo enquanto o lado direito é negativo. Esta igualdade só é satisfeita se os dois lados forem nulos e isto só ocorre com $t=0$. Vemos inclusive que, fora deste ponto, $P^{x}>P^{y}$ sempre. Com isto, temos também que não há pontos de equilíbrio entre as três estratégias no interior do simplex, pois em nenhum ponto o payoff das três estratégias é o mesmo. No vértice dos All-C, com $y=1$,

$$
P^{x}=\frac{-k c \alpha}{1+H \alpha \beta}
$$




$$
P^{y}=-k c \alpha
$$

Apesar de $P^{x}$ ser menor que $P^{y}$, ambos são negativos e a tendência é a invasão dos exploradores. Já no ponto dos Disc, com $x=1$,

$$
P^{x}=k c \alpha \frac{\alpha B H-1}{1+\alpha H}
$$

e

$$
P^{y}=k c \alpha \frac{\alpha B H-1}{1+\alpha H}-k c \alpha \frac{(B+1) H \alpha \beta}{1+H \alpha \beta} .
$$

Vemos que, se $\alpha H B>1, P^{x}>0$, ainda fazendo com que a seleção não favoreça a invasão dos exploradores, mesmo com uma condição um pouco mais restritiva. Mas o payoff dos cooperadores incondicionais é sempre menor que o dos discriminadores (vemos que a fração a mais na expressão de $P^{y}$ é sempre positiva), como já esperávamos. Portanto, nessas condições, a estratégia Disc forma uma ESS e não é invadida por outras estratégias, constituindo a melhor resposta para si mesma.

Analisando a dinâmica da lateral em que $y=0$, na ausência de All-C,

$$
P^{x}=k c \alpha \frac{x^{2} B H \alpha-1}{1+x H \alpha}
$$

e

$$
P^{y}=k c \alpha \frac{x^{2} B H \alpha-1}{1+x H \alpha}-k c \alpha \frac{H x(1-x) \alpha}{1+H x \alpha}-k c \alpha \frac{x^{2}(H(B+1) \alpha \beta}{1+H x \alpha \beta} .
$$

Ao igualarmos $P^{x}$ a zero, tiramos o ponto de equilíbrio instável entre os Disc e os All-D

$$
x^{*}=\frac{1}{\sqrt{\alpha H B}} .
$$

Este equilíbrio existe para $\alpha H B>1$, pois $x$ deve ser menor que um. Notamos que, para pequenos erros de execução (em um cenário realista, espera-se que os erros de execução ocorram em uma frequência baixa), ou seja, para $\alpha$ próximo de 1 , a seleção consegue favorecer 
a cooperação em uma gama de cenários plausíveis. Com isso vemos novamente a dinâmica separada em dois casos, dependendo do valor de $\alpha H B$.

$\mathrm{Na}$ lateral onde não há cooperadores condicionais, com $x=0$,

$$
P^{x}=-k c \alpha \frac{1+\alpha H y^{2}}{1+\alpha H y}+k c \alpha \frac{y^{2} H \alpha \beta}{1+H y \alpha \beta}
$$

e

$$
P^{y}=-k c \alpha .
$$

São resultados semelhantes ao caso sem erros. Aqui os Disc também não conseguem ter payoff maior que os All-D. Ao fazermos $P^{x}=0$, temos a igualdade

$$
\alpha^{2} H y^{2}+\alpha \beta H y=-1 .
$$

A expressão à esquerda é sempre maior ou igual a zero, pois todos os seus termos são positivos ou nulos (somente no caso em que $y=0$ ). Analisando os payoffs na lateral sem exploradores, em que $t=1$,

$$
P^{x}=k c \alpha \frac{H \alpha(B x+x-1)-1}{1+\alpha H}+k c \alpha \frac{H(1-x) \alpha \beta}{1+H \alpha \beta}
$$

e

$$
P^{y}=k c \alpha \frac{H \alpha(B x+x-1)-1}{1+\alpha H}-k c \alpha \frac{x H(B+1) \alpha \beta}{1+H \alpha \beta} .
$$

Enfatizamos aqui que, ao invés de termos um equilíbrio indiferente entre os cooperadores, temos uma tendência dos Disc dominarem a população. Agora, sabemos que no ponto em que $x=1$, em um extremo desta linha, $P^{x}>0$ no caso em que $\alpha H B>1$, enquanto $P^{x}<0$ no outro extremo, em que $y=1$. Ao longo da linha, o payoff dos cooperadores condicionais passa pelo zero, igualando-se ao dos exploradores. $O$ ponto onde $P^{x}=0$ é representado por

$$
x^{*}=\frac{1+\alpha H}{\alpha H B+\alpha^{2} H(\beta H B+1)} .
$$




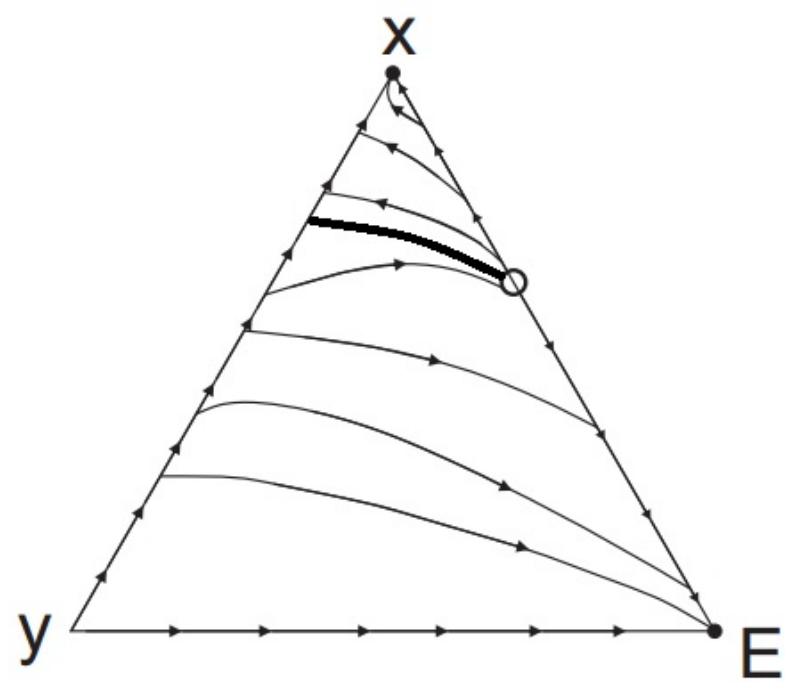

Figura 3.5- Simplex da dinâmica com erros de execução para HB $>1$. A representação no simplex mostra que o vértice x é uma ESS, levando a população a uma dominação efetiva dos Disc quando esta se encontra acima do limiar, representado pela linha mais grossa, novamente ligando os dois pontos de equilíbrio entre os Disc e os All-D nas laterais.

Fonte: Elaborada pelo autor.

Estando no caso onde este ponto de equilíbrio ocorre, temos $\alpha H B>1$, que são os dois termos da esquerda na fração. Se o termo da direita no denominador for maior que o termo da direita no numerador, esta fração é menor que um. Vemos que isto ocorre também quando $\alpha H B>1$. Portanto, esta é a fração de indivíduos da estratégia Disc em que ocorre o equilíbrio entre estes e os cooperadores. No interior do simplex, ligando este ponto e o ponto de equilíbrio entre as duas estratégias na linha em que $y=0$ novamente existe uma curva ao longo da qual $P^{x}=0$. Acima desta curva, a seleção favorece os Disc; abaixo desta curva, a seleção favorece os All-D. Mas desta vez a estratégia Disc também é uma ESS. O simplex da Fig. 3.5 esboça a dinâmica, mostrando a possibilidade de dominação dos discriminadores.

Vimos aqui uma possibilidade de implementação de erros de execução, mostrando a capacidade da evolução estável de uma forma de cooperação mais complexa, mais apta a vencer a exploração, em um ambiente ainda mais próximo da realidade. Vimos que, neste ambiente, a presença dos All-C não afeta os Disc por deriva. 


\subsection{Má reputação nas interações entre exploradores}

Nowak e Ghang, no artigo onde introduzem a estratégia de interações opcionais ${ }^{53}$, mencionam a diferença em relação aos outros modelos no caso de interações entre dois exploradores. Os autores dizem que os exploradores, ao jogarem, não alteram suas reputações, ou pode-se entender que simplesmente não jogam. Anteriormente, mais comumente considerava-se esta exploração como causadora de má reputação entre os exploradores envolvidos. A forma com que trabalham o cálculo, com população finita e considerando a história de exploração de cada explorador, os autores consideraram esta forma comum agora difícil de ser considerada analiticamente, deixando-a para considerações futuras. Com este tratamento em populações infinitas que estamos utilizando, vemos ser consideravelmente mais fácil analisar esta alternativa. De imediato, podemos perceber que esta mudança favorece o sucesso da cooperação, pois agora mais facilmente os exploradores são marcados com má reputação. Tomamos a população de cooperadores condicionais e exploradores, analisada no começo do capítulo. A forma com que o payoff é calculado em termos da fração de indivíduos com má reputação, $b_{n}$, não se altera. Temos

$$
P_{n}^{E}=b x-\frac{b x}{1-x} b_{n}
$$

e

$$
P_{n}^{C}=(b x-c)+c b_{n}
$$

A mudança aparece na forma de $b_{n}$. Desta vez, ao invés de ganharem má reputação com probabilidade $Q$ somente quando encontram cooperadores, os exploradores de boa reputação correm este risco em todas as suas interações. Vamos considerar que a probabilidade de serem descobertos quando interagem entre si é um valor diferente $P$, naturalmente menor ou igual a $Q$. Depois, analisamos o caso particular em que $P=Q . b_{n}$ segue a relação

$$
b_{n}=b_{n-1}+\left(1-x-b_{n-1}\right)(x Q+[1-x] P)=
$$




$$
=b_{n-1}(1-x Q-[1-x] P)+(1-x)(x Q+[1-x] P) .
$$

Vemos que a alteração é simplesmente uma mudança $x Q \rightarrow[x Q+(1-x) P]$, então temos o resultado para $b_{n}$

$$
b_{n}=(1-x)\left(1-[1-x Q-\{1-x\} P]^{n-1}\right) .
$$

Os cálculos são os mesmos, temos somente que no final a expressão transforma $x Q \rightarrow$ $[x Q+(1-x) P]$, então temos os payoffs médios

$$
P^{E}=c k\left(\frac{(B+1) x}{1+(k-1)(Q x+[1-x] P)}\right)
$$

e

$$
P^{C}=c k\left(B x-\frac{1-x}{1+(k-1)(Q x+[1-x] P)}\right) .
$$

Esta alteração não deve modificar a condição para a estabilidade da cooperação, $H B>1$, com $H=(k-1) Q$, pois o payoff de um único explorador em uma população de cooperadores não se altera em relação ao caso original. Vemos isto ao fazer $P^{C}>P^{E}$ para $x=1$. No entanto, o valor do ponto de equilíbrio instável interno, originalmente $x^{*}=(B H)^{-1 / 2}$, torna-se

$$
x^{*}=\frac{\left[B^{2} H^{\prime 2}+4 B\left(H-H^{\prime}\right)\right]^{1 / 2}-B H^{\prime}}{2 B\left(H-H^{\prime}\right)} .
$$

Ao fazermos $P^{C}=P^{E}$ para $x=x^{*}$ e definindo $(k-1) P=H^{\prime}$. Com estas definições, os payoffs ficam

$$
P^{E}=c k\left(\frac{(B+1) x}{1+\left(H x+H^{\prime}[1-x]\right)}\right)
$$

e

$$
P^{C}=c k\left(B x-\frac{1-x}{1+\left(H x+H^{\prime}[1-x]\right)}\right) .
$$

Os gráficos desta situação na Fig. 3.6, na Fig. 3.7 e na Fig. 3.8 mostram a relação entre 


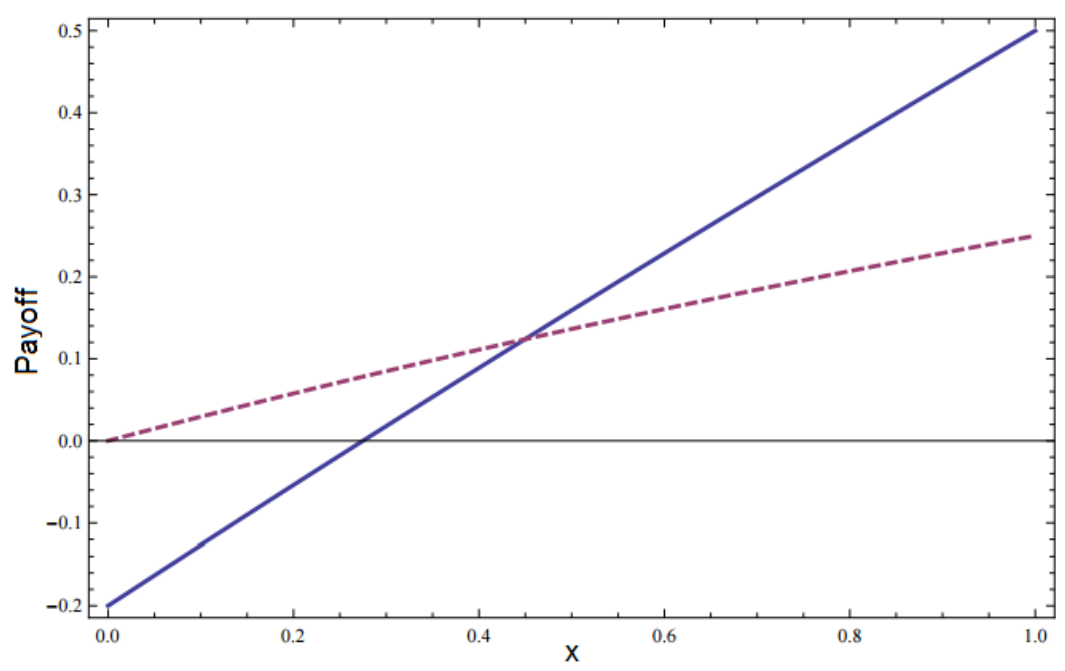

Figura 3.6- Payoffs para má reputação entre os exploradores com $\mathbf{P}=\mathbf{0 . 4}$ e $\mathbf{H B}>\mathbf{1}$. Tomamos os parâmetros $\mathrm{B}=0.5, \mathrm{Q}=0.5$ e $\mathrm{k}=11$, de forma que $\mathrm{H}=5$ e $\mathrm{H}^{\prime}=4$. $\mathrm{HB}=2.5$ e a cooperação é uma ESS para este valor de $P$. A curva tracejada representa $P^{E}$ enquanto a outra curva representa $P^{C}$. Reescalamos os payoffs com o fator comum $k c$.

Fonte: Elaborada pelo autor.

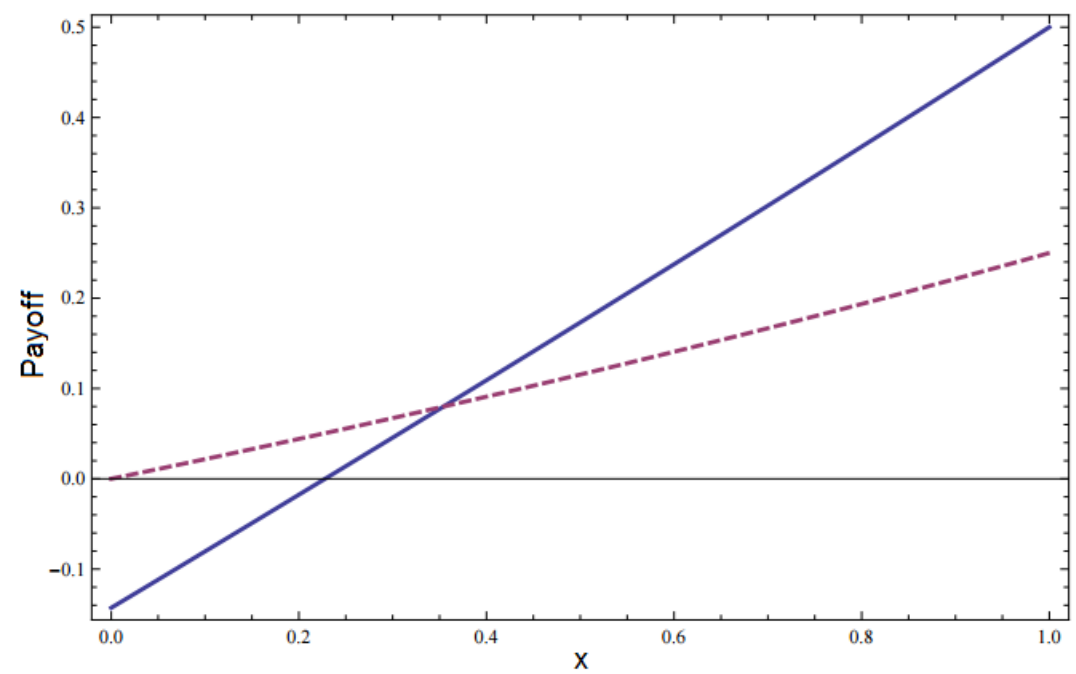

Figura 3.7- Payoffs para má reputação entre os exploradores com $\mathbf{P}=\mathbf{0 . 6}$ e $\mathbf{H B}>\mathbf{1}$. Tomamos os parâmetros $B=0.5, Q=0.5$ e $k=11$, de forma que $H=5$ e $H^{\prime}=6$. $H B=2.5$ e a cooperação ainda é uma ESS para este valor de $P$. O ponto que as curvas se cruzam apenas é deslocado para a esquerda, quer dizer que é uma melhor situação para a cooperação, naturalmente. A curva tracejada representa $P^{E}$ enquanto a outra curva representa $P^{C}$. Reescalamos os payoffs com o fator comum $k c$.

Fonte: Elaborada pelo autor. 


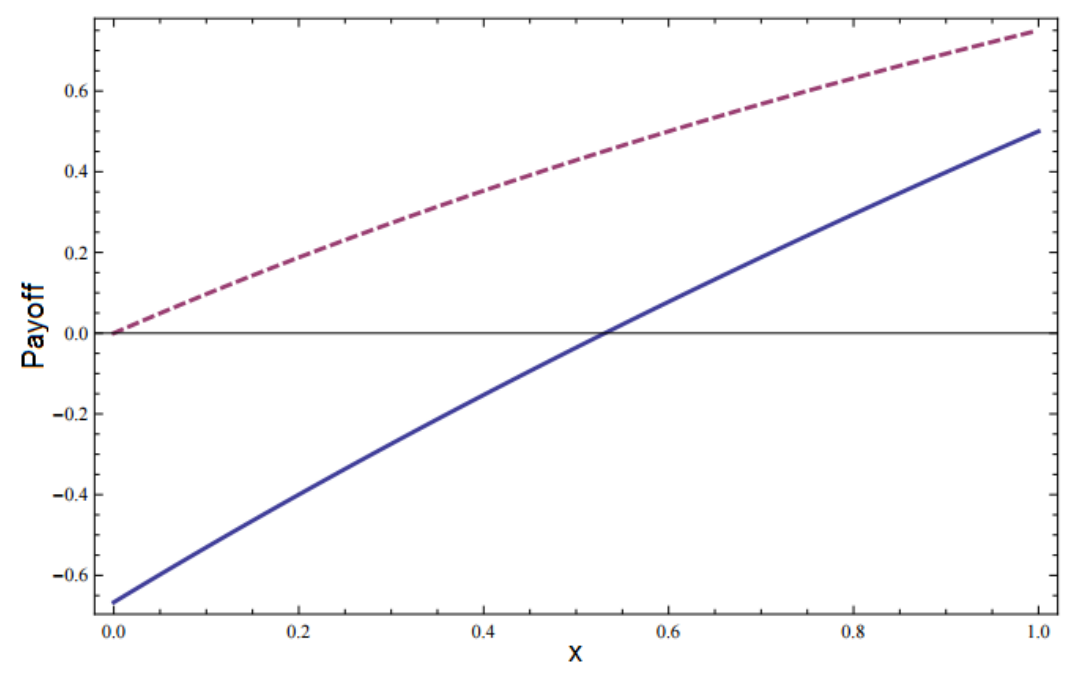

Figura 3.8- Payoffs para má reputação entre os exploradores com $\mathbf{P}=\mathbf{0 . 5}$ e $\mathbf{H B}<\mathbf{1}$. Tomamos os parâmetros $B=0.5, Q=0.1$ e $k=11$, de forma que $H=1$ e $H^{\prime}=5$. $H B=0.5$ e a cooperação não é mais uma ESS. Vemos aqui graficamente que as curvas são mais afetadas pelo valor de $H B$ do que pelo valor de $H^{\prime}$. A curva tracejada representa $P^{E}$ enquanto a outra curva representa $P^{C}$. Reescalamos os payoffs com o fator comum $k c$.

Fonte: Elaborada pelo autor.

os payoffs para diferentes valores de $P$; vemos que a dinâmica não muda, dependendo apenas do valor de $H B$.

No caso particular em que $H=H^{\prime}$ temos que $x^{*}=(B H)^{-1}$. O equilíbrio é deslocado para o lado dos cooperadores de tal forma que em média a seleção favorece a cooperação em uma população inicial uniformemente aleatória para o caso $H B>2$ ao invés da condição $H B>4$ do modelo original. Esta alteração é também insuficiente para afetar a estabilidade dos exploradores, com certeza, pois qualquer forma de cooperação está em desvantagem em uma população somente de exploradores.

Então, se tomarmos $P=Q$, temos os valores de payoff

$$
P^{E}=c k\left(\frac{(B+1) x}{1+H}\right)
$$

e

$$
P^{C}=c k\left(B x-\frac{1-x}{1+H}\right) .
$$

Os gráficos desta situação na Fig. 3.9 e na Fig. 3.10 mostram casos em que $H B>1$ e $H B<1$ nesta condição. Vemos que o payoff dos cooperadores é favorecido em relação ao 


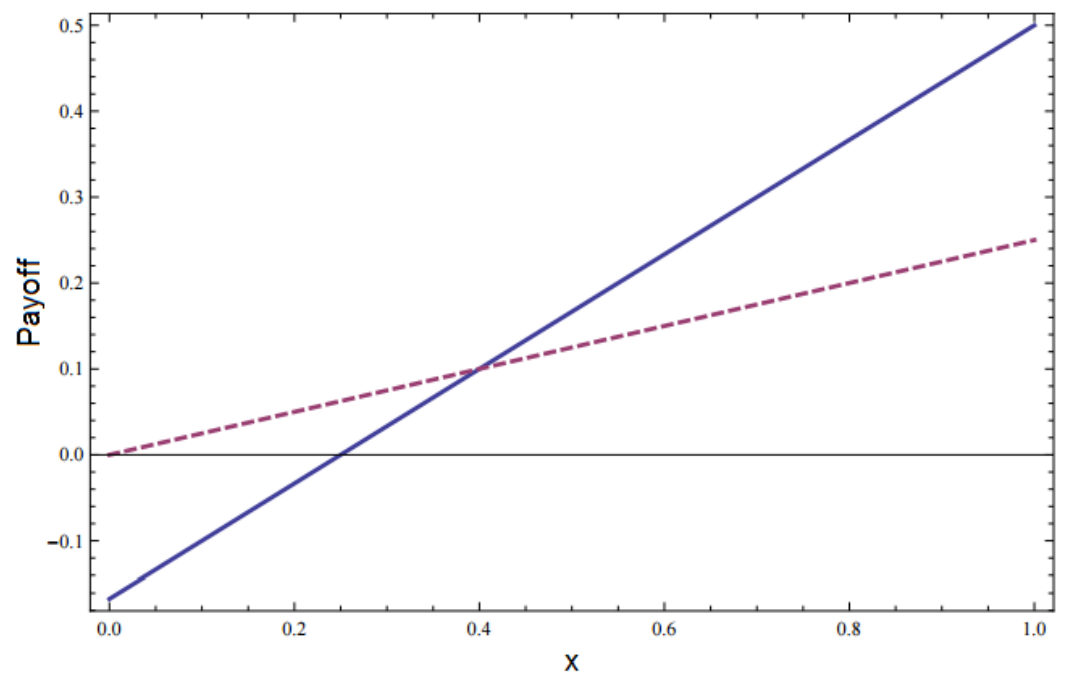

Figura 3.9- Payoffs para má reputação entre os exploradores com $\mathbf{H}=\mathbf{H}^{\prime}$ e $\mathbf{H B}>\mathbf{1}$. Tomamos os parâmetros $B=0.5, Q=P=0.5$ e $k=11$, de forma que $H=5$. Assim, $H B=2.5$, neste caso a cooperação forma uma ESS. A curva tracejada representa $P^{E}$ enquanto a outra curva representa $P^{C}$. Reescalamos os payoffs com o fator comum $k c$.

Fonte: Elaborada pelo autor.

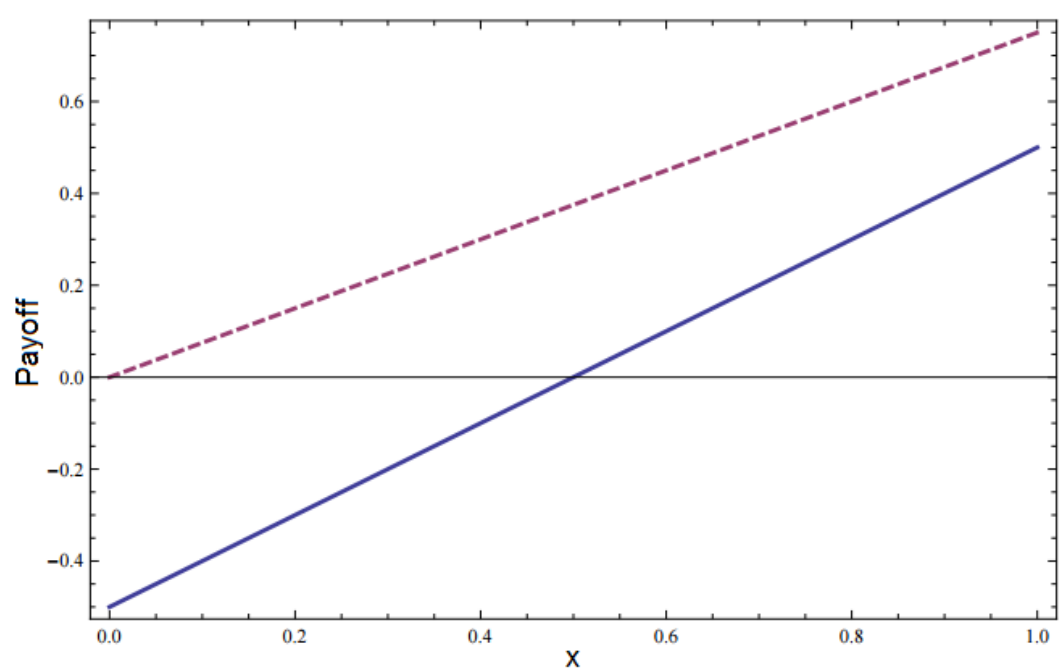

Figura 3.10- Payoffs para má reputação entre os exploradores com $\mathbf{H}=\mathbf{H}^{\prime}$ e $\mathbf{H B}<\mathbf{1}$. Tomamos os parâmetros $B=0.5, Q=P=0.1$ e $k=11$, de forma que $H=1$. Assim, $H B=0.5$ e os exploradores dominam a dinâmica. A curva tracejada representa $P^{E}$ enquanto a outra curva representa $P^{C}$. Reescalamos os payoffs com o fator comum $k c$.

Fonte: Elaborada pelo autor. 
modelo original.

Nesta seção vimos a dinâmica entre a estratégia All-D e a estratégia Disc no caso em que os exploradores podem adquirir má reputação ao jogarem entre si, proposta por Nowak e Ghang em seu artigo, onde consideramos que os discriminadores observam a tendência não cooperativa dos dois exploradores, mesmo que estes não consigam efetivamente explorar um ao outro.

\subsection{Um modelo para informação incompleta}

Aqui, consideramos que a má reputação de um explorador pode não ser conhecida por todos os cooperadores, ou da mesma forma, que o cooperador simplesmente erra em aceitar um jogo com o explorador de má reputação. Pode ser compreendido como um caso de informação incompleta no sentido de que, com alguma chance, os cooperadores aceitarão jogar com alguém de má reputação, como se uma fração correspondente da população não soubesse dessa reputação. A limitação dessa abordagem está no fato de que essa probabilidade é constante, representando uma taxa de efetividade da população, sem evoluir no tempo. Um modelo com informação incompleta e crescente ${ }^{55}$ e outro com interações privadas ${ }^{56}$ foram recentemente abordados de forma não analítica. Analisamos esta modificação no modelo de interações opcionais, considerando que todos os indivíduos jogam em cada rodada. Com probabilidade $P$, um jogo que não era pra ser aceito ocorre. Assim, o payoff de um explorador na rodada $n$ é

$$
P_{n}^{E}=\frac{b_{n}}{1-x} x P b+\frac{1-x-b_{n}}{1-x} x b=x b-\frac{x b(1-P)}{1-x} b_{n}
$$

com $b_{n}$ sendo a fração de indivíduos com má reputação na rodada $n$. O payoff dos exploradores é lido como: se este possuir má reputação estabelecida, ao se encontrar com um cooperador, recebe $b$ com probabilidade $P$ e, ao se encontrar com outro explorador, não recebe payoff. Se este ainda possui boa reputação, ao se encontrar com um cooperador, recebe $b$ e, ao se encontrar com outro explorador, não recebe payoff. Da mesma forma, o payoff de um cooperador é 


$$
P_{n}^{C}=x(b-c)+\left(1-x-b_{n}\right)(-c)+b_{n} P(-c)=b x-c+(1-P) c b_{n} .
$$

Para um cooperador: ao se encontrar com outro cooperador, este recebe $(b-c)$; ao se encontrar com um explorador com má reputação, recebe $(-c)$ com probabilidade $P$ e, ao se encontrar com um explorador de boa reputação, recebe $(-c)$.

A função $b_{n}$ segue a mesma relação de recorrência da versão original, pois aqui nada é mudado na forma com que os exploradores recebem má reputação. Temos

$$
b_{n}=b_{n-1}+\left(1-x-b_{n-1}\right) x Q=b_{n-1}(1-Q x)+(1-x) Q x .
$$

Resolvendo a recorrência, como em detalhes no início do capítulo, temos para $b_{n}$ o valor

$$
b_{n}=(1-x)\left[1-(1-Q x)^{n-1}\right] .
$$

Depois de uma rodada, a probabilidade de ocorrer outra rodada é $w$. Com isso, já vimos que

$$
P^{E}=\sum_{n=1}^{\infty} P_{n}^{E} w^{n-1} ; \quad P^{C}=\sum_{n=1}^{\infty} P_{n}^{C} w^{n-1} .
$$

Como já fizemos anteriormente,

$$
\begin{gathered}
\sum_{n=1}^{\infty} b_{n} w^{n-1}=(1-x)\left[\sum_{n=1}^{\infty} w^{n-1}-\sum_{n=1}^{\infty}(w(1-Q x))^{n-1}\right] \\
\therefore \sum_{n=1}^{\infty} b_{n} w^{n-1}=\frac{(1-x) w Q x}{(1-w)(1-w+w Q x)}
\end{gathered}
$$

Desta forma, o payoff médio de um explorador durante toda a geração é

$$
\begin{gathered}
P^{E}=x b \sum_{n=1}^{\infty} w^{n-1}-\frac{x b(1-P)}{1-x} \sum_{n=1}^{\infty} w^{n-1} b_{n}= \\
=\frac{b x}{1-w}-x b(1-P) \frac{w Q x}{(1-w)(1-w+w Q x)}=k c\left[(B+1)\left(\frac{x+P H x^{2}}{1+H x}\right)\right]
\end{gathered}
$$


Onde definimos os mesmos $k=\frac{1}{1-w}, B=\frac{b-c}{c}$ e $H=(k-1) Q$. O payoff de um cooperador em uma geração fica

$$
\begin{gathered}
P^{C}=(b x-c) \sum_{n=1}^{\infty} w^{n-1}+ \\
=k c\left[B x-\frac{1-x}{1+H x}-\frac{P H x(1-x)}{1+H x}\right] \\
=
\end{gathered}
$$

Temos, portanto

$$
P^{E}=k c\left[(B+1)\left(\frac{x+P H x^{2}}{1+H x}\right)\right]
$$

e

$$
P^{C}=k c\left[B x-\frac{1-x}{1+H x}-\frac{P H x(1-x)}{1+H x}\right] .
$$

Com os payoffs médios de cada indivíduo em uma geração calculados, podemos utilizar a equação dos replicadores para analisar os pontos de equilíbrio

$$
\dot{x}=x\left[P^{C}(x)-\phi(x)\right], \quad \phi(x)=P^{C}(x) x+P^{E} x(1-x) .
$$

Podemos reescrevê-la na forma

$$
\dot{x}=x(1-x)\left[P^{C}(x)-P^{E}(x)\right] .
$$

Substituindo os valores de payoff, temos

$$
\dot{x}=k c x(1-x)\left[B x-\left(\frac{(1-x)(1+x H P)-(B+1)\left(x+x^{2} H P\right.}{1+H X}\right)\right] .
$$

Fazendo $\dot{x}=0$, vemos que a equação tem três pontos de equilíbrio, $x=0, x=1$ e o ponto de equilíbrio interno 


$$
x^{*}=\frac{H P-\left[H^{2} P^{2}+4 B H(1-P)\right]^{1 / 2}}{2 B H(1-P)} .
$$

Se $P^{C}(0)<P^{E}(0)$, o ponto $x=0$ é um equilíbrio estável, e portanto, a estratégia dos exploradores é uma ESS. Esta condição nos dá $k c<0$, o que nunca acontece. Assim, a estratégia dos exploradores é uma ESS. Para o caso dos cooperadores, devemos ter $P^{C}(1)>$ $P^{E}(1)$, que é o mesmo que a relação

$$
B H>\frac{1+P H}{1-P} .
$$

Se esta inequação for satisfeita, a estratégia dos cooperadores forma uma ESS. Aqui podemos observar como o parâmetro $P$ altera a condição para estabilidade da cooperação, imposta sobre o termo de custo-benefício $B$ e a duração média da geração ponderada pel taxa de descoberta dos exploradores $H$. Conforme $P$ se aproxima de um, a restrição aumenta dramaticamente, até mesmo podendo impossibilitar o sucesso da cooperação (caso em que os discriminadores, na verdade, perdem sua capacidade de discriminar, aproximando-se da estratégia dos cooperadores incondicionais; este cenário é interpretado como a incapacidade total de transmitir a informação sobre a descoberta de um explorador, mesmo havendo a descoberta). Também vemos que, para $P=0$, reobtemos o resultado do modelo original.

Para o ponto de equilíbrio interno, devemos ter $\frac{d P^{C}\left(x^{*}\right)}{d x}>\frac{d P^{E}\left(x^{*}\right)}{d x}$ para que este seja um equilíbrio estável. Esta relação nos dá

$$
B H\left(x^{*}\right)^{2}+2 B\left(x^{*}\right)+H<0 .
$$

Esta relação nunca se satisfaz, pois temos o polinômio à esquerda sempre positivo. Portanto, o equilíbrio é instável. Os gráficos na Fig. 3.11 e na Fig. 3.12 indicam a relação entre os payoffs para diferentes valores de $P$, novamente mostrando um caso em que a cooperação pode ser bem sucedida e também mostrando a situação limiar em que o valor de $P$ causa a igualdade da condição para estabilidade da cooperação.

Nesta seção vimos como a incerteza de discriminação ou a existência de uma fração da população de discriminadores que não reconhece uma dada reputação pode afetar a restrição 


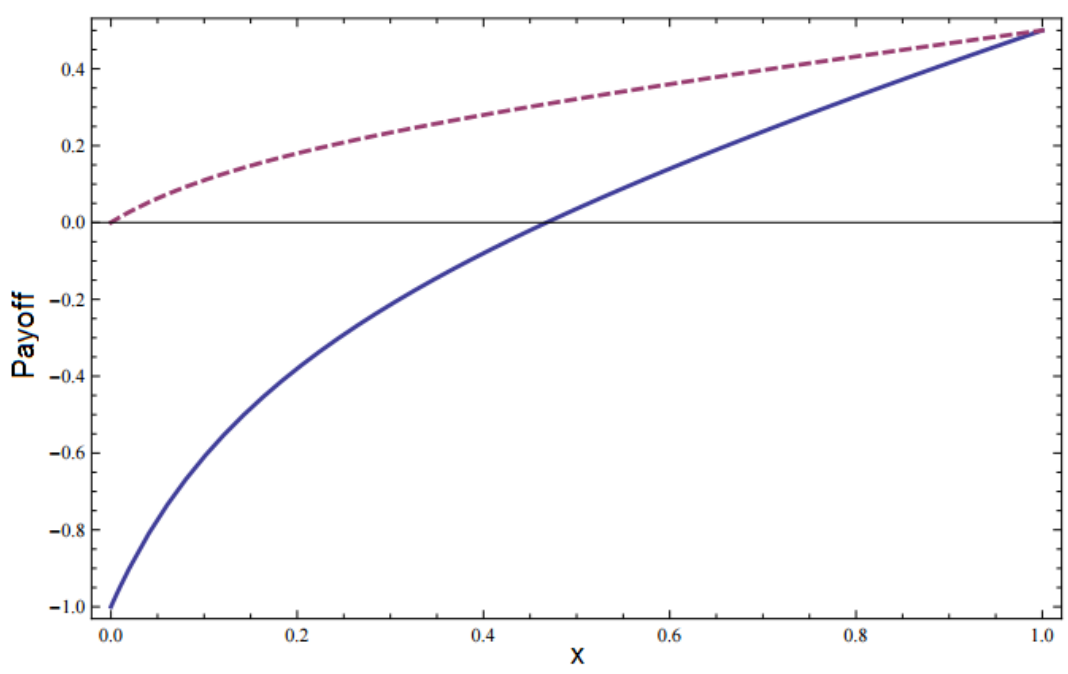

Figura 3.11- Payoffs para informação incompleta com $P=0.2$. Tomamos os parâmetros $\mathrm{B}=0.5, \mathrm{Q}=0.5$ e $\mathrm{k}=11$, de forma que $\mathrm{H}=5$. Para estes parâmetros, este é justamente o valor máximo de $P$ que permite que os cooperadores formem uma ESS. Nesta situação, no ponto em que os cooperadores dominam a população, um mutante explorador tem o mesmo sucesso. Para valores menores de $P$, as duas curvas passam a se cruzar antes de $x=1$. A curva tracejada representa $P^{E}$ enquanto a outra curva representa $P^{C}$. Reescalamos os payoffs com o fator comum $k c$.

Fonte: Elaborada pelo autor.

para a razão custo-benefício da cooperação e o número médio de rodadas ponderado pela taxa de descoberta de uma má reputação. Um interessante e simples resultado analítico abordando o importante aspecto da informação incompleta. 


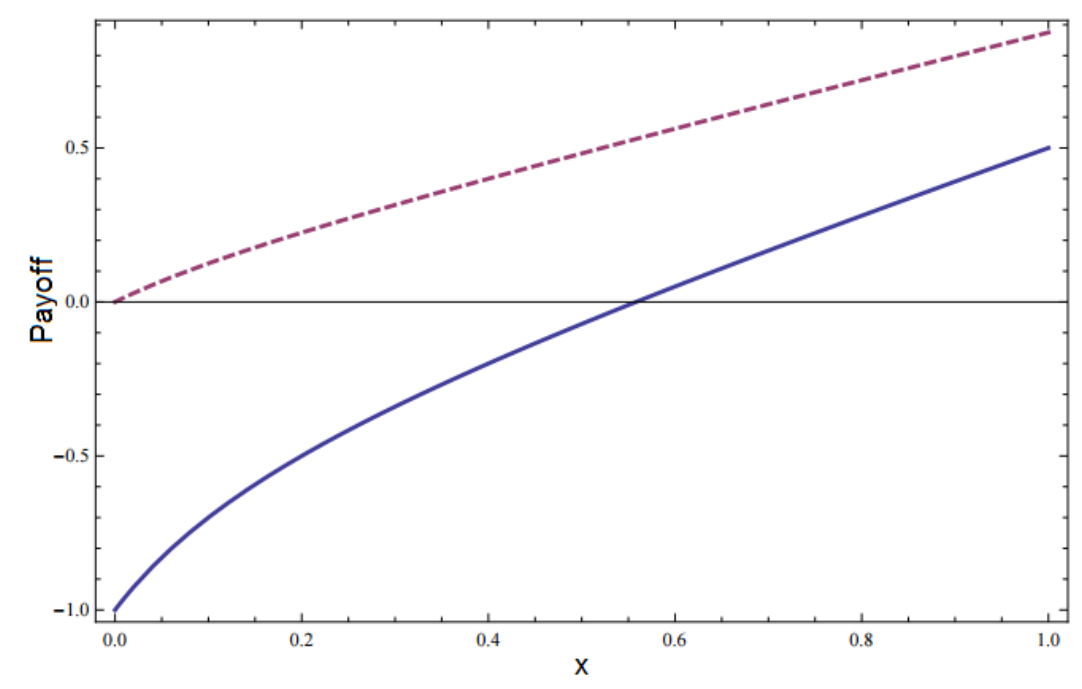

Figura 3.12- Payoffs para informação incompleta com $P=0.5$. Tomamos os parâmetros $B=0.5, Q=0.5$ e $\mathrm{k}=11$, de forma que $\mathrm{H}=5$. Aqui estamos em uma situação onde $P$ é maior que o limite para a estabilidade da cooperação, portanto os exploradores são sempre bem sucedidos, mesmo tendo $H B>1$, naturalmente. A curva tracejada representa $P^{E}$ enquanto a outra curva representa $P^{C}$. Reescalamos os payoffs com o fator comum $k c$.

Fonte: Elaborada pelo autor. 


\section{Capítulo 4}

\section{Conclusões}

Este trabalho teve por objetivo mostrar um aspecto do desenvolvimento do modelo de reciprocidade indireta de Nowak e Sigmund para então trabalhar em uma expansão semelhante da variação de interações opcionais. Modificamos os cálculos do artigo sobre interações opcionais seguindo a técnica do modelo de 1998 para então mostrar que, neste caso, a presença de cooperadores incondicionais é capaz de fazer a cooperação falhar na disputa contra exploradores. Também desenvolvemos um caminho para implementação de erros de execução, capazes de restituir o equilíbrio dos discriminadores mesmo na presença dos cooperadores condicionais.

Também conseguimos apresentar outras duas modificações; uma delas sugerida pelos próprios autores, mostrando apenas o efeito de uma pequena alteração no endereçamento de reputações; a outra introduzindo maior realidade à modelagem, representando uma forma de implementação de informações incompletas, de forma a dificultar o sucesso da cooperação.

Estes modelos nos mostram, de forma simplificada, uma possibilidade teórica para a viabilização da reciprocidade indireta em um ambiente de pressão seletiva. Não sabemos como a fixação da cooperação ocorreu de fato no passado, mas é importante entendermos a ação de mecanismos que a tornaram possível, dando luz a diversos modos de resolver a aparente contradição entre os mecanismos de evolução e a cooperação.

Além disso, muitos testes experimentais vêm sendo realizados com a intenção de mapear a forma de atuação destes mecanismos para a cooperação em seres humanos ${ }^{20-24}$, inclusive de reciprocidade indireta. Há uma grande concordância entre resultados teóricos e o que é observado experimentalmente na observação do comportamento real. 
Avanços futuros incluem análises de probabilidades de fixação de mutantes em populações dominadas por uma estratégia, propostas de modelos em populações estruturadas com indivíduos possuindo diferentes graus de aproximação e simulações computacionais de situações mais realísticas, como populações finitas.

Por fim, devemos considerar que nosso passado evolutivo guarda muitas informações sobre o nosso funcionamento e sobre a sociedade em que vivemos; ${ }^{57}$ como nossa grande capacidade cognitiva, a conquista da linguagem e a emergência do pensamento consciente. E todos os esforços, teóricos e experimentais, nos aproximam de uma maior compreensão destes fenômenos e, consequentemente, de um maior domínio da realidade que nos constrói e é construída por nós. 


\section{Referências}

1 DARWIN, C. On the origin of species. London: J. Murray, 1859.

2 MENDEL, G. Experiments in plant hybridisation. New York: Cosimo inc., 2008.

3 RIDLEY, M. Evolution. Oxford: Oxford University Press, 2004.

4 NOWAK, M. A. Evolutionary dynamics. Cambridge: Harvard University Press, 2006.

5 AVERY, J. Information theory and evolution. Singapore: World Scientific, 2003.

6 DAWKINS, R. The selfish gene. Oxford: Oxford University Press, 2006.

7 SMITH, J. M.; SZATHMARY, E. The major transitions in evolution. Oxford: Oxford University Press, 1997.

8 TRAULSEN, A.; NOWAK, M. A. Evolution of cooperation by multilevel selection. Proceedings of the National Academy of Sciences, v. 103, n. 29, p. 10952-10955, 2006.

9 AXELROD, R.; HAMILTON, W. D. The evolution of cooperation. Science, v. 211, n. 4489, p. 1390-1396, 1981.

10 SMITH, J. M. Group selection and kin selection. Nature, v. 201, n. 4924, p. 1145-1147, 1964.

11 BOWLES, S.; GINTIS, H. A cooperative species: human reciprocity and its evolution. Princeton: Princeton University Press, 2011.

12 TRIVERS, R. L. The evolution of reciprocal altruism. Quarterly Review of Biology, v. 46, n. 1 , p. 35-57, 1971.

13 NOWAK, M.; SIGMUND, K. A strategy of win-stay, lose-shift that outperforms tit-for-tat in the prisoner's dilemma game. Nature, v. 364, n. 6432, p. 56-58, 1993. 
14 AXELROD, R. The evolution of strategies in the iterated prisoner's dilemma. The Dynamics of Norms, p. 1-16, 1987.

15 NOWAK, M.; SIGMUND, K. Oscillations in the evolution of reciprocity. Journal of Theoretical Biology, v. 137, n. 1, p. 21-26, 1989.

16 RICHERSON, P. J.; BOYD, R. Not by genes alone: how culture transformed human evolution. Chicago: Chicago University Press, 2008.

17 FEHR, E.; GÄCHTER, S. Altruistic punishment in humans. Nature, v. 415, n. 6868, p. 137-140, 2002.

18 BERG, J.; DICKHAUT, J.; MCCABE, K. Trust, reciprocity, and social history. Games and Economic Behavior, v. 10, n. 1, p. 122-142, 1995.

19 BOYD, R.; SILK, J. B. How humans evolved. New York: WW Norton \& Company, 2009.

20 MILINSKI, M.; SEMMANN, D.; KRAMBECK, H.-J. Reputation helps solve the 'tragedy of the commons'. Nature, v. 415, n. 6870, p. 424-426, 2002.

21 YOELI, E.; HOFFMAN, M.; RAND, D. G.; NOWAK, M. A. Powering up with indirect reciprocity in a large-scale field experiment. Proceedings of the National Academy of Sciences, v. 110, n. 2, p. 10424-10429, 2013.

22 ROBERTS, G. Evolution of direct and indirect reciprocity. Proceedings of the Royal Society of London B, v. 275, n. 1631, p. 173-179, 2008.

23 WEDEKIND, C.; MILINSKI, M. Cooperation through image scoring in humans. Science, v. 288, n. 5467, p. $850-852,2000$.

24 SEINEN, I.; SCHRAM, A. Social status and group norms: indirect reciprocity in a repeated helping experiment. European Economic Review, v. 50, n. 3, p. 581-602, 2006.

25 NOWAK, M. A.; SIGMUND, K. Evolution of indirect reciprocity by image scoring. Nature, v. 393, n. 6685, p. $573-577,1998$.

26 VON NEUMANN, J.; MORGENSTERN, O. Theory of games and economic behavior. Princeton: Princeton University Press, 2007.

27 NOWAK, M.; SIGMUND, K. Game-dynamical aspects of the prisoner's dilemma. Applied Mathematics and Computation, v. 30, n. 3, p. 191-213, 1989.

28 GIBBONS, R. Game theory for applied economists. Princeton: Princeton University Press, 1992. 
29 SUGDEN, R. The economics of rights, co-operation and welfare. Oxford: Blackwell, 1986.

30 SMITH, J. M.; PRICE, G. The logic of animal conflict. Nature, v. 246, p. 15-18, 1973. doi: $10.1038 / 246015 \mathrm{a} 0$.

31 SMITH, J. M. The theory of games and the evolution of animal conflicts. Journal of Theoretical Biology, v. 47, n. 1, p. 209-221, 1974.

32 PAGE, K. M.; NOWAK, M. A. Unifying evolutionary dynamics. Journal of Theoretical Biology, v. 219, n. 1, p. 93-98, 2002.

33 SMITH, J. M. Evolution and the theory of games. Cambridge: Cambridge University Press, 1982.

$34 \mathrm{NASH}$, J. F. Equilibrium points in n-person games. Proceedings of the National Academy of Sciences of the United States of .America, v. 36, n. 1, p. 48-49, 1950.

35 HOFBAUER, J.; SIGMUND, K. Evolutionary games and population dynamics. Cambridge: Cambridge University Press, 1998.

36 NOWAK, M. A.; SIGMUND, K. The dynamics of indirect reciprocity. Journal of Theoretical Biology, v. 194, n. 4, p. 561-574, 1998.

37 LEIMAR, O.; HAMMERSTEIN, P. Evolution of cooperation through indirect reciprocity. Proceedings of the Royal Society of London B, v. 268, n. 1468, p. 745-753, 2001.

38 PANCHANATHAN, K.; BOYD, R. A tale of two defectors: the importance of standing for evolution of indirect reciprocity. Journal of Theoretical Biology, v. 224, n. 1, p. 115-126, 2003.

39 BRANDT, H.; SIGMUND, K. The good, the bad and the discriminator-errors in direct and indirect reciprocity. Journal of Theoretical Biology, v. 239, n. 2, p. 183-194, 2006.

40 NOWAK, M. A. Five rules for the evolution of cooperation. Science, v. 314, n. 5805, p. 1560-1563, 2006.

41 NOWAK, M. A. Evolving cooperation. Journal of Theoretical Biology, v. 299, p. 1-8, 2012. doi: 10.1016/j.jtbi.2012.01.014.

42 NOWAK, M. A.; SIGMUND, K. Evolution of indirect reciprocity. Nature, v. 437, n. 7063, p. 1291-1298, 2005.

43 KANDORI, M. Social norms and community enforcement. The Review of Economic Studies, v. 59, n. 1, p. 63-80, 1992. 
44 OHTSUKI, H.; IWASA, Y. The leading eight: social norms that can maintain cooperation by indirect reciprocity. Journal of Theoretical Biology, v. 239, n. 4, p. 435-444, 2006.

45 OHTSUKI, H.; IWASA, Y. Global analyses of evolutionary dynamics and exhaustive search for social norms that maintain cooperation by reputation. Journal of Theoretical Biology, v. 244, n. 3, p. 518-531, 2007.

46 OHTSUKI, H.; IWASA, Y. How should we define goodness?-reputation dynamics in indirect reciprocity. Journal of Theoretical Biology, v. 231, n. 1, p. 107-120, 2004.

47 RAND, D. G.; NOWAK, M. A. Human cooperation. Trends in Cognitive Sciences, v. 17, n. 8 , p. $413-425,2013$.

48 OHTSUKI, H.; HAUERT, C.; LIEBERMAN, E.; NOWAK, M. A. A simple rule for the evolution of cooperation on graphs and social networks. Nature, v. 441, n. 7092, p. 502-505, 2006.

49 TANABE, S.; SUZUKI, H.; MASUDA, N. Indirect reciprocity with trinary reputations. Journal of Theoretical Biology, v. 317, p. 338-347, 2013. doi: 10.1016/j.jtbi.2012.10.031.

50 NAKAMARU, M.; IWASA, Y. The coevolution of altruism and punishment: role of the selfish punisher. Journal of Theoretical Biology, v. 240, n. 3, p. 475-488, 2006.

51 PANCHANATHAN, K.; BOYD, R. Indirect reciprocity can stabilize cooperation without the second-order free rider problem. Nature, v. 432, n. 7016, p. 499-502, 2004.

52 NAKAMURA, M.; OHTSUKI, $\mathrm{H}$. Indirect reciprocity in three types of social dilemmas. Journal of Theoretical Biology, v. 355, p. 117-127, 2014. doi: 10.1016/j.jtbi.2014.03.035.

53 GHANG, W.; NOWAK, M. A. Indirect reciprocity with optional interactions. Journal of Theoretical Biology, v. 365, p. 1-11, 2015. doi: 10.1016/j.jtbi.2014.09.036.

54 BOLTON, G. E.; KATOK, E.; OCKENFELS, A. Cooperation among strangers with limited information about reputation. Journal of Public Economics, v. 89, n. 8, p. 1457-1468, 2005.

55 OLEJARZ, J.; GHANG, W.; NOWAK, M. A. Indirect reciprocity with optional interactions and private information. Games, v. 6, n. 4, p. 438-457, 2015.

56 OHTSUKI, H.; IWASA, Y.; NOWAK, M. A. Reputation effects in public and private interactions. PLOS Computational Biology, v. 11, n. 11, p. e1004527, 2015.

57 BJORKLUND, D. F.; PELLEGRINI, A. D. The origins of human nature: evolutionary developmental psychology. Washington: American Psychological Association, 2002. 